\title{
Review
}

\section{Nickel-Based Electrocatalysts for Water Electrolysis}

\author{
Zuraya Ángeles-Olvera ${ }^{\dagger}$, D. Alfonso Crespo-Yapur, Oliver Rodríguez ${ }^{\ddagger}$, Jorge L. Cholula-Díaz, Luz María Martínez \\ and Marcelo Videa (1D*
}

School of Engineering and Sciences, Tecnologico de Monterrey, Monterrey, N.L. c.p 64849 Mexico; zuraya.elisa.angeles.olvera@umontreal.ca, alfonso.crespo@tec.mx, jorgeluis.cholula@tec.mx, luzvidea@tec.mx * Correspondence: mvidea@tec.mx; Tel.: +52-8183-582-0000

† Current address: Université de Montréal. Montréal, QC H2X 0A9. Canada

$\ddagger$ Current address: Beckman Institute for Advanced Science and Technology, University of Illinois at Urbana-Champaign, Urbana, IL, 61801 United States

\begin{abstract}
Current hydrogen production is based on the reforming process leading to the emission of pollutants; therefore, a substitute production method is imminently required. Water electrolysis is an ideal alternative for large-scale hydrogen production, as it does not produce any carbon-based pollutant byproducts. Production of green hydrogen from water electrolysis using intermittent sources (e.g., solar, eolic) would facilitate clean energy storage. However, the electrocatalysts currently required for water electrolysis are noble metals, making this potential option expensive and inaccessible for industrial applications. Therefore, there is a need to develop electrocatalysts based on earth-abundant and low-cost metals. Nickel-based electrocatalysts are a fitting alternative because they are economically accessible. Extensive research has focused on developing nickelbased electrocatalysts for hydrogen and oxygen evolution. Theoretical and experimental work have addressed the elucidation of these electrochemical processes and the role of heteroatoms, structure, and morphology. Even though some works tend to be contradictory, they have lit up the path for efficient nickel-based electrocatalysts. For these reasons, herein, a review of recent progress is presented.
\end{abstract}

Keywords: water electrolysis; nickel; earth-abundant metals; electrocatalysis; HER; OER

\section{Water electrolysis}

One of the main motivations to produce molecular hydrogen $\left(\mathrm{H}_{2}\right)$ is its role as an energy carrier, with an energy density of $140 \mathrm{MJ} \mathrm{kg}^{-1}$ [1], which makes it an ideal alternative for clean energy storage. Water electrolysis, the electrical decomposition of water $\left(\mathrm{H}_{2} \mathrm{O}\right)$ into $\mathrm{H}_{2}$ and molecular oxygen $\left(\mathrm{O}_{2}\right)$ [2], is considered a clean and efficient $\mathrm{H}_{2}$ production method since no byproducts are generated, and renewable energies can be used, in contrast to the reforming process, where carbon dioxide $\left(\mathrm{CO}_{2}\right)$ and carbon monoxide (CO) are generated [3]. Although water electrolysis has been known for more than 200 years and provides high purity $\mathrm{H}_{2}$ (greater than 99.5\%) [4], it represents less than $1 \%$ of the total amount of $\mathrm{H}_{2}$ produced each year globally [5].

The overall reaction for water electrolysis is shown in Eq. 1 [6].

$$
\mathrm{H}_{2} \mathrm{O}_{(\mathrm{l})} \rightarrow \mathrm{H}_{2}(\mathrm{~g})+\frac{1}{2} \mathrm{O}_{2}(\mathrm{~g})
$$

The electrical work needed for the water electrolysis according to Eq. 1 at standard temperature and pressure is given by the change in free energy, $\Delta_{\mathrm{rxn}} G^{\theta}=237.2 \mathrm{~kJ} / \mathrm{mol}$. It marks the thermodynamic lower limit of energy required for producing hydrogen, which in practical terms is equivalent to $33 \mathrm{kWh}$ per $1 \mathrm{~kg}$ of hydrogen at an equilibrium voltage of $1.23 \mathrm{~V}$. In the best-case scenario, the electrical energy consumed by an electrolyzer is about $50 \mathrm{kWh}$, corresponding to an efficiency of $66 \%$ [7]. Typical operating voltages go from 1.60 to $2.00 \mathrm{~V}$. 
Water electrolysis consists of two electrochemical reactions that occur in parallel at two different electrodes: the cathodic hydrogen evolution reaction (HER) and the anodic oxygen evolution reaction (OER) [8]. A water electrolysis cell consists of an anode, a cathode, a power source, and an electrolyte. When an electrical current is applied to the electrochemical system, electrons flow from the negatively charged source to the cathode to produce $\mathrm{H}_{2}$. In parallel, to maintain the electrochemical balance, ions travel across the electrolyte to the anode, and they give up electrons to produce $\mathrm{O}_{2}$ [4].

Understanding the mechanism of water electrolysis is fundamental for the efficient production of $\mathrm{H}_{2}$. Among the main limitations for its industrial scalability is the OER efficiency at the anode. When comparing the OER mechanism with the HER mechanism, the first one is thermodynamically and kinetically more demanding, as it requires the sequential transfer of four electrons and the need to break oxygen-hydrogen bonds to form oxygen-oxygen bonds [9,10].

As stated above, water electrolysis is a process composed of two main reactions: HER and OER. It could be acidic, alkaline, or neutral, depending on the electrolyte composition. The selection of water electrolysis conditions must ensure that the electrolytic system: $i$ ) be chemically and electrochemically stable, $i i)$ dissolve the electrolyte to provide a conductive solution, and iii) be easy to handle and store. Meanwhile, the supporting electrolyte must be inert and have high mobility ions to improve the conductivity of the solution [11].

In acidic electrolytes HER and OER reactions proceed according to Eq. 2 and Eq. 3:

$$
\begin{aligned}
4 \mathrm{H}^{+}+4 \overline{\mathrm{e}} & \rightarrow 2 \mathrm{H}_{2} \\
2 \mathrm{H}_{2} \mathrm{O} & \rightarrow 4 \mathrm{H}^{+}+\mathrm{O}_{2}+4 \overline{\mathrm{e}}
\end{aligned}
$$

while in alkaline electrolytes these reactions take place following Eq. 4 and Eq. 5:

$$
\begin{aligned}
4 \mathrm{H}_{2} \mathrm{O}+4 \overline{\mathrm{e}} & \rightarrow 2 \mathrm{H}_{2}+4 \mathrm{OH}^{-} \\
4 \mathrm{OH}^{-} & \rightarrow \mathrm{O}_{2}+2 \mathrm{H}_{2} \mathrm{O}+4 \overline{\mathrm{e}}
\end{aligned}
$$

Both HER and OER have multi-step mechanisms, with more than one possible pathway. The cathodic half-reaction, HER, involves three steps: Volmer, Tafel, and Heyrowsky; and it can proceed via two mechanisms: the Volmer-Tafel or the Volmer-Heyrovsky [12].

During the Volmer step, a faradaic reaction generates a hydrogen atom which is adsorbed on the surface of the catalyst. This can occur either from the reduction of a proton in acidic media (see Eq. 6), or from the reduction of a water molecule in alkaline electrolytes, as shown by Eq. 9 [12].

The formation of $\mathrm{H}_{2}$ from the adsorbed hydrogen atoms can proceed via the Tafel or Heyrovsky steps. The formation of $\mathrm{H}_{2}$ by the Tafel step (Eq. 7) consists of the combination of two hydrogen atoms previously adsorbed on the catalyst to produce a $\mathrm{H}_{2}$ molecule that will later be desorbed. On the other hand, the Heyrovsky step, Eq. 8 or Eq. $10, \mathrm{H}_{2}$ is formed by the cathodic formation of an hydrogen atom that bonds with an $\mathrm{H}_{\mathrm{ad}}$ formed by the Volmer step. [12-14].

\section{Acidic conditions:}

Volmer step:

$$
2 \mathrm{H}_{3} \mathrm{O}^{+}+\mathrm{M}+2 \overline{\mathrm{e}} \rightarrow 2 \mathrm{MH}_{\mathrm{ad}}+2 \mathrm{H}_{2} \mathrm{O}
$$

Tafel step:

$$
2 \mathrm{MH}_{\mathrm{ad}} \rightarrow \mathrm{H}_{2}+2 \mathrm{M}
$$

Heyrovsky step:

$$
\mathrm{MH}_{\mathrm{ad}}+\mathrm{H}^{+}+\overline{\mathrm{e}} \rightarrow \mathrm{H}_{2}+\mathrm{M}
$$


Alkaline conditions:

Volmer step:

$$
2 \mathrm{H}_{2} \mathrm{O}+\mathrm{M}+2 \overline{\mathrm{e}} \rightarrow 2 \mathrm{MH}_{\mathrm{ad}}+2 \mathrm{OH}^{-}
$$

Tafel step:

$$
2 \mathrm{MH}_{\mathrm{ad}} \rightarrow \mathrm{H}_{2}+2 \mathrm{M}
$$

Heyrovsky step:

$$
\mathrm{MH}_{\mathrm{ad}}+\mathrm{H}_{2} \mathrm{O}+\overline{\mathrm{e}} \rightarrow \mathrm{H}_{2}+\mathrm{M}+\mathrm{OH}^{-}
$$

One of the factors determining the preferred mechanism is the surface coverage of

$\mathrm{H}_{\mathrm{ad}}$. At high coverage, the Volmer-Tafel mechanism will dominate since the surface recombination step becomes more probable, while at low coverage, the Volmer-Heyrovsky mechanism will be favored [13]. The free energy of hydrogen adsorption $\left(\Delta G_{H}\right)$ indicates the strength of the metal-hydrogen bond and must also be taken into account. If this bonding energy is too negative, the Volmer step is favored, but the strong MH bond will be difficult to break, thus impeding the other steps. In contrast, a positive $\Delta G_{H}$ would make the Volmer step less likely to occur, which would slow down the HER. Another factor that must be considered is the stability of the catalyst at different $p \mathrm{H}$ values; non-noble metals are unstable in acidic media but can perform well in alkaline media. Combinations of non-noble metals with non-metals can be used to make materials with high catalytic activity in a wide range of $p \mathrm{H}$ [13]. In summary, the electrocatalytic material determines the mechanism followed by HER. The choice of electrocatalyst implies a choice of electrolyte $p \mathrm{H}$ since the stability of the former limits this.

The other half-reaction in water electrolysis, OER, involves the transfer of four electrons. The mechanism followed by OER depends on the electrocatalyst used, and the $p \mathrm{H}$ of the electrolyte [13]. The mechanisms that have been reported for different catalytic materials present variations in the intermediates involved in the overall reaction, mainly in the reaction that precedes the formation of $\mathrm{O}_{2}[14,15]$. There are two main routes for the formation of $\mathrm{O}_{2}$ : the first one is the direct combination of two adsorbed oxygen atoms (MO), Eq. 13; the second one is the formation of an oxyhydroxide intermediate $(\mathrm{MOOH})$, Eq. 14 and Eq. 18, which will then, upon an oxidation step, decompose to $\mathrm{O}_{2}$ $[14,15]$. Even though there have been discrepancies in the mechanism reported for OER, and these vary depending on the electrocatalytic conditions, there are three principal intermediates involved: the oxide $(\mathrm{MO})$, the hydroxide $(\mathrm{MOH})$, and the oxyhydroxide $(\mathrm{MOOH})$ [13]. Furthermore, the efficiency of OER depends on the interactions between electrocatalytic material and intermediates [15]. Due to these thermodynamic and kinetic limitations, the OER requires the application of high overpotential values $[3,16]$.

\section{Acidic conditions:}

$$
\begin{aligned}
\mathrm{M}+\mathrm{H}_{2} \mathrm{O} & \rightarrow \mathrm{MOH}+\mathrm{H}^{+}+\overline{\mathrm{e}} \\
\mathrm{MOH} & \rightarrow \mathrm{MO}+\mathrm{H}^{+}+\overline{\mathrm{e}} \\
2 \mathrm{MO} & \rightarrow 2 \mathrm{M}+\mathrm{O}_{2} \\
\mathrm{MO}+\mathrm{H}_{2} \mathrm{O} & \rightarrow \mathrm{MOOH}+\mathrm{H}^{+}+\overline{\mathrm{e}} \\
\mathrm{MOOH}+\mathrm{H}_{2} \mathrm{O} & \rightarrow \mathrm{M}+\mathrm{O}_{2}+\mathrm{H}^{+}+\overline{\mathrm{e}}
\end{aligned}
$$


Alkaline conditions:

$$
\begin{aligned}
\mathrm{M}+\mathrm{OH}^{-} & \rightarrow \mathrm{MOH}+\overline{\mathrm{e}} \\
\mathrm{MOH}+\mathrm{OH}^{-} & \rightarrow \mathrm{MO}+\mathrm{H}_{2} \mathrm{O}+\overline{\mathrm{e}} \\
2 \mathrm{MO} & \rightarrow 2 \mathrm{M}+\mathrm{O}_{2} \\
\mathrm{MO}+\mathrm{OH}^{-} & \rightarrow \mathrm{MOOH}+\overline{\mathrm{e}} \\
\mathrm{MOOH}+\mathrm{OH}^{-} & \rightarrow \mathrm{M}+\mathrm{O}_{2}+\mathrm{H}_{2} \mathrm{O}+\overline{\mathrm{e}}
\end{aligned}
$$

Acid electrolytes are commonly used on acid proton exchange membranes[14]. The main advantage of using an acid electrolyte for water electrolysis is the high concentration of protons available for HER $[17,18]$. Nevertheless, acidic water electrolysis requires the implementation of noble metals $\left(\mathrm{Pt}\right.$, Ir, or $\mathrm{Ru}$ ) or noble metal oxides $\left(\mathrm{IrO}_{2}\right.$ or $\left.\mathrm{RuO}_{2}\right)$ as electrocatalysts for HER or OER, respectively $[17,19,20]$. In the electrolysis cell's anode, the potential working range is only suitable for noble metals due to their resistance to aggressive and corrosive environments and their insolubility in acids, giving them a long operating life [19-21]. The use of non-noble metals as electrocatalysts in acidic conditions leads to the dissolution of oxides and hydroxides, causing the loss of stability due to changes in the structural and chemical composition of the electrocatalyst $[19,20]$. This explains the scarcity of cost-effective electrocatalysts for acid water electrolysis [22].

A common alternative to acid electrolytes is the implementation of alkaline electrolytes, like $\mathrm{KOH}$ and $\mathrm{NaOH}$. These are strong bases with high mobility ions [23]. Due to the low availability of protons in the media, the catalytic activity and exchange current density for HER are low compared to the values reported for acid electrolytes [12]. On the other hand, the main advantage is that alkaline electrolytes provide better stability for non-noble metals since there is no corrosion and risk of dissolution [11,18,24]. The possibility of selecting non-noble metals, like earth-abundant metals, as electrocatalyst materials, make them a cost-effective alternative for industrial applications $[14,17,20]$.

Like alkaline electrolytes, neutral electrolytes enable the use of first-row transition metals as catalysts since the corrosion rate of catalysts under strong acids or bases can also be reduced by using a neutral electrolyte. However, neutral electrolytes have the drawback that HER requires high overpotentials to dissociate water molecules to generate protons, slowing down the kinetics of this reaction [25]. Neutral electrolytes allow the use of bifunctional catalysts, which simplifies the electrochemical systems and can lead to a significant reduction in costs. Neutral media also allows the direct use of seawater as a neutral electrolyte $[25,26]$ and the combination of metal-based electrocatalyst with biocatalysts for the production of biofuels [26].

\section{Electrocatalysis}

The dependence of the electron transfer rate on the electrode material suggests that the electrochemical reaction is electrocatalytic, and the electrode acts as an electrocatalyst. An electrocatalyst-electrolyte interface has a heterogeneous distribution composed of multiple phases, of which one or more can catalyze the elementary steps of the reaction. These phases are anchored to a material with a high surface area that stabilizes the area of the electrocatalyst, acting as a support phase [27]. A detailed characterization of the material must be done to evaluate the activity of an electrocatalyst, and its performance parameters must be determined.

The performance parameters of an electrocatalyst provide information on the electrochemical properties of the electrocatalytic system [15,28]. Some key performance parameters are the overpotential, the Tafel slope, the exchange current density, the turnover frequency, faradaic efficiency, electrochemical active surface area, and stability $[14,15]$. These parameters are determined by general electrochemical characterization techniques like linear sweep voltammetry, cyclic voltammetry, and electrochemical impedance spectroscopy [29]. The kinetics parameters give information about the reaction mechanism, and the rate-determining step [15]. 
The overpotential $\eta$ is the difference between the equilibrium potential $E_{\mathrm{eq}}$ and the applied potential $E_{\text {app }}$ (Eq. 20) at which the electrocatalyst provides a given current as a result of the excess potential introduced to overcome the energetic barrier of the reaction. $[15,30]$.

$$
\eta=E_{\mathrm{app}}-E_{\mathrm{eq}}
$$

The Butler-Volmer (Eq. 21) describes the rate of an electrochemical reaction through the current density $(j)$ in terms of the overpotential [31]. As the scan rate controls the speed at which the potential is swept, $j$ is proportional to the reaction rate [32]. The lower the $\eta$ required to maintain a specific $j$, the more efficient the electrocatalytic material [33]. In this equation, $j_{0}$ is the exchange current density, $\alpha$ is the transfer coefficient, $f$ represents the Faraday constant divided by the temperature and the real gas constant (i.e., $f=F / R T$ ), and $n$ is the number of electrons transferred.

$$
j=j_{0}\left\{e^{-\alpha f \eta}-e^{(1-\alpha) f \eta}\right\}
$$

The Butler-Volmer equation represents the sum of reduction and oxidation reaction currents. These currents are proportional to the rate of reaction. In equilibrium, the total flux of current is zero because the system has reached a dynamic equilibrium in which the rate of oxidation-reduction (redox) reactions is the same [34]. Otherwise, only one process is dominant at high $\eta$ values. This eliminates one term leading to Tafel's equation [35], which can be expressed as the linearized Eq. 22.

$$
\eta=m_{T} \ln j_{0}-m_{T} \ln j \quad m_{T}=\frac{R T}{\alpha F}
$$

The Tafel slope, $m_{T}$, describes how sensitive the current response is to the overpotential and gives information about the reaction mechanism and the rate-limiting steps [35]. A small Tafel slope is attributed to a rapid increase in the $j$ at lower $\eta$ values [15]. Equally, the exchange current density $\left(j_{0}\right)$ can be obtained by the Tafel equation (Eq. 22) that corresponds to the intercept [14]. $j_{0}$ is proportional to the rate reaction at the equilibrium when the total current is equal to zero, and the anodic and cathodic currents are equal $[15,36]$. This kinetic parameter depends on the concentration, temperature, electrode catalyst loading, and its specific surface area [36]. It reflects the intrinsic bonding/chargetransfer interactions between the electrocatalyst and the electroactive species [15]. A high value of $j_{0}$ indicates that the material is a promising electrocatalyst for the target reaction $[15,36]$. These three kinetic parameters can be determined experimentally by voltammetry, specifically linear sweep voltammetry (LSV). Voltammetry is a dynamic electrochemical technique that allows the observation of the relations between applied potential and current. The structure of the voltammogram obtained (shape, size, and potential peaks) gives information about the electrochemical processes active on the surface of the working electrode $[37,38]$. In LSV, the current is monitored while the potential is being ramped from an initial potential to a final potential, covering a range of interest [38]. The current is plotted against the potential to produce a linear sweep voltammogram [39]. The overpotential is determined by Eq. 20, and the standard potential value [40].

From the voltammogram and using Eq. 22 Tafel curves can be plotted to find the Tafel slope. For instance, Yu et al. used LSV to determine the Tafel slope of three different deposits, namely $\mathrm{Pt}, \alpha-\mathrm{Ni}(\mathrm{OH})_{2} / \mathrm{Pt}$ and $\beta-\mathrm{Ni}(\mathrm{OH})_{2} / \mathrm{Pt}$, and determined that the $\beta-\mathrm{Ni}(\mathrm{OH})_{2} / \mathrm{Pt}$ deposit had the highest electrocatalytic activity because this material presented the smaller Tafel slope $\left(39 \mathrm{mV} \mathrm{s}^{-1}\right)$ [41]. Figures $1 \mathrm{a}$ and $1 \mathrm{~b}$ show the voltammograms and the Tafel plots with their corresponding slopes, respectively. 

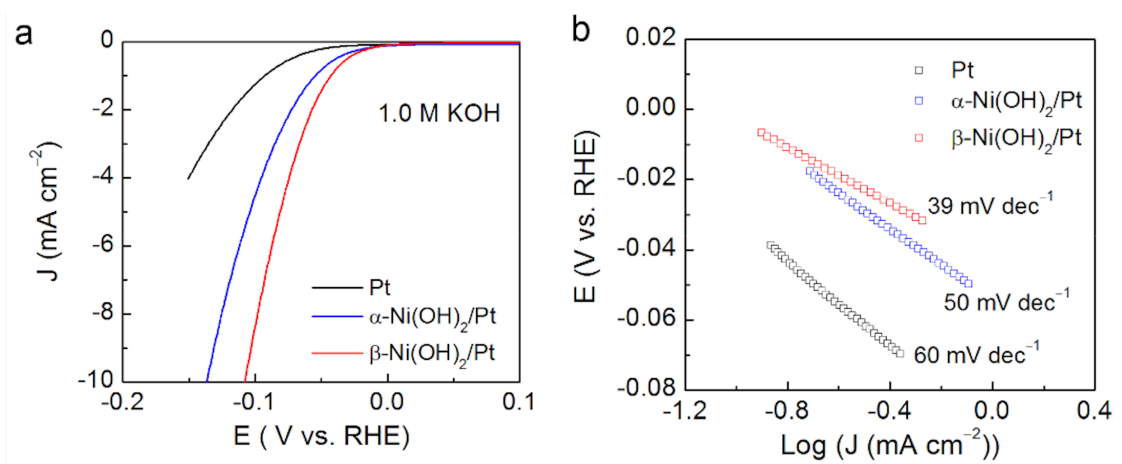

Figure 1. (a) Linear sweep voltammograms of $\mathrm{Pt}, \alpha-\mathrm{Ni}(\mathrm{OH})_{2} / \mathrm{Pt}$ and $\beta-\mathrm{Ni}(\mathrm{OH})_{2} / \mathrm{Pt}$ in $\mathrm{KOH} 1 \mathrm{M}$ at $10 \mathrm{mV} \mathrm{s}^{-1}$. (b) Tafel plots corresponding to the voltammograms in (a). Modified from [41].

The turnover frequency (TOF) is a performance parameter that evaluates the rate at which reactants are converted to products per catalyst site per second [42,43]. The TOF values depend on the temperature, and pressure [43]. The equation for the determination of TOF in gas evolving reactions is stated in Eq. 23, where $j$ is the current density, $N_{A v}$ is the Avogadro number, $n$ the number of electrons involved, $F$ the Faraday's constant, and $\Gamma$ is the surface or total concentration of active sites.

$$
\mathrm{TOF}=\frac{j N_{A v}}{n F \Gamma}
$$

TOF values between $10^{-3}$ and $10^{-2} \mathrm{~s}^{-1}$ have been observed [43]. The main limitation for the accurate determination of this parameter is the difficulty of determining the number of active sites. There is an overestimation in the counting of active species in the electrochemical system because it includes chemically inert or buried sites [14,43]. Also, the calculation of $\Gamma$ for multimetallic, non-metallic and mixed oxide catalysts on a large scale are limited due to its difficulty [43]. An accurate method for the approximation of $\Gamma$ for monometallic films is integrating the peak of a redox reaction characteristic of the material, obtained by cyclic voltammetry (CV), that corresponds to the reaction of interest. This method only considers metallic sites that directly participate in the redox reaction [14].

$\mathrm{CV}$ is commonly used to investigate the redox process of molecular species. This technique also allows the study of the electron transfer-initiated chemical reactions, like electrocatalysis [32]. Videa et al. reported the determination of $\Gamma$ for $\mathrm{Ni}(\mathrm{OH})_{2}$ in alkaline media by using $\mathrm{CV}$ and Eq. 24, where $\mathrm{\Gamma}_{\mathrm{Ni}(\mathrm{OH})_{2}}$ is the superficial concentration of $\mathrm{Ni}(\mathrm{OH})_{2}, Q$ is the area under the redox peak involved in the formation of $\mathrm{Ni}(\mathrm{OH})_{2}, F$ is Faraday constant and $n$ the number of transferred electrons in the redox process. By integrating the area under the redox peak, $\mathrm{I}_{\mathrm{af}}$ (Figure 2), involved in the formation of the electroactive species, $\mathrm{Ni}(\mathrm{OH})_{2}$, the charge is related to $\Gamma_{\mathrm{Ni}(\mathrm{OH})_{2}}$ according to Eq. 24 [44]

$$
\Gamma_{\mathrm{Ni}(\mathrm{OH})_{2}}=\frac{Q}{n F A} .
$$




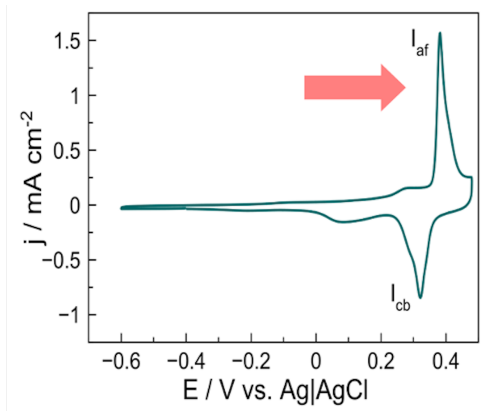

Figure 2. Cyclic voltammetry for nickel deposited in a gold electrode in $1 \mathrm{M} \mathrm{KOH}$. Modified from [44]

The electrochemical active surface area (ECSA) is a fundamental electrochemical property of an electrified interface, it is the electrode surface area that is accessible for charge transfer, or storage [45]. The values of ECSA depend on the electrochemical reaction that takes place in the interface and the materials involved [14,45]. Because every catalytic process takes place on the electroactive surface, extensive quantities obtained in electrochemical experiments must be normalized concerning ECSA. Since changes in the ECSA during an experiment may occur, it is necessary to monitor this property between experiments [46]. Despite its relevance in electrochemical processes, its determination is limited to inert and approximate planar electrode substrates, becoming complicated for porous materials [45]. Some methods that have been reported for the determination of ECSA are the integration of the redox peak areas, the hydrogen underpotential deposition, carbon monoxide stripping, and the double-layer capacitance $\left(C_{D L}\right)$. Capacitive characteristics of an interface in an electrochemical system, like $C_{D L}$, are associated with the charge storage phenomenon. This phenomenon occurs at potential values at which there is no solvent decomposition or electron transfer during the potential application in the interface [47]. $C_{D L}$ can be determined by two techniques: CV $[23,48]$ and electrochemical impedance spectroscopy (EIS) [48]. For the CV technique, the first step is to identify the non-faradaic range of the system in a specific electrolyte for measurements at different scan rates. The current measured $\left(i_{C}\right)$ in this potential window is attributed to the capacitive double-layer charge. When plotted against the scan rate $(v)$, the slope of the curve gives the value of $C_{D L}$ according to Eq. 25 .

$$
i_{C}=v C_{D L}
$$

Finally, to obtain the ECSA, the value of $C_{D L}$ is divided by the specific capacitance of the sample at the same electrolyte $\left(C_{S}\right)($ Eq. 26) $[48,49]$.

$$
\mathrm{ECSA}=\frac{C_{D L}}{C_{S}} .
$$

The second technique for the determination of $C_{D L}$ is electrochemical impedance spectroscopy (EIS). This technique is useful for the characterization of the electrode/ electrolyte interface. It gives an insight into the kinetic properties of an electrocatalytic reaction, and in a simple electrochemical approach [50,51]. This technique has also been previously reported for the study of electrocatalytic reactions, like OER [48-52]. Electrical impedance is the resistance of a system to the flow of current at a specific frequency [53]. An alternating current (ac) potential is applied at a range of frequencies to measure the impedance. The potential values applied must be associated with the redox reaction studied. Electrochemical processes, like charge transfer, ion diffusion and capacitance, can be identified on the basis of their frequency-dependent current response $[49,51,52,54]$. Once that the EIS spectra are obtained, data is fitted to an equivalent circuit, in which each component of the circuit is related to an interfacial parameter 
$[49,52,54]$. The interfacial parameters obtained by EIS depend on the environment in which the charge transfer occurs, on the electrolyte's composition, and the electrode $[49,54]$. The determination of $C_{D L}$ for monometallic films has proven to be a reliable technique, comparable to CV $[55,56]$. For deposits with multiple components, like NiFe bimetallic films and high conductivity EIS is better than CV due to the elimination of the interference of redox and OER currents [48,52]. After the measurement of $C_{D L}$ by EIS, the determination of ECSA is carried out as mentioned above. Batchellor et al. confirmed the accuracy of the ECSA determination by EIS; they obtained an increase of three orders of magnitude in the value of the $C_{D L}$ in the charged state compared to the uncharged state [52]. Finally, from the estimate of ECSA, the roughness factor (RF) can be determined. RF is obtained by the division of the real area by the geometric area [23]. The roughness of a material can be related to the distribution, size, and morphology of the electrocatalyst particles; a rough surface is characterized by irregularity in its structure. Thus, it gives information about the geometry and distribution of active sites [57]. An RF bigger than one indicates a larger and more favorable area for adsorption [58].

There is a need to increase electrocatalyst stability to meet industrial applications without sacrificing its electrochemical activity [14]. The stability of non-noble metal electrocatalyst is an issue at the industrial level due to the high current densities involved $[14,59]$. Some catalyst deactivation processes that have been related to low stability are corrosion, material degradation, surface passivation, and catalyst film delamination. Also, in terms of film thickness, a thick film will have more stability compared to a thinner deposit of the same material [60]. A typical test for the evaluation of stability is the accelerated durability test. In this test, the electrocatalyst is subjected to hundreds or thousands of voltammetry cycles at a high scan rate. Before and after this cyclic step, LSV is conducted to evaluate changes in the material activity. Small changes in the $\eta$ indicate the electrocatalyst's stability.

\section{Nickel-based electrocatalysts}

Even though water electrolysis has the advantage of producing extremely pure hydrogen ( $>99.9 \%)$, it is limited by its energy efficiency, safety, durability, operability, portability, and the high costs of installation and operation [11]. That is why the development of low-cost electrocatalytic materials that efficiently couple electron transfer in HER and OER reactions at low overpotential values are of importance [61], [62]. The characteristics of a promising electrocatalyst are a lower overpotential at a current density, lower Tafel slope, and excellent stability [63]. So far, noble metal-based electrocatalysts are the most efficient electrocatalysts for water electrolysis; platinum (Pt) for HER and ruthenium $\left(\mathrm{RuO}_{2}\right)$ and iridium $\left(\mathrm{IrO}_{2}\right)$ oxides for OER [64], [65]. However, the implementation of noble metals and their alloys for water electrolysis limits the industrial scalability due to their high costs and scarcity [61,62]. An attractive alternative is the implementation of transition metals, like $\mathrm{Co}, \mathrm{Ni}, \mathrm{Fe}$, or $\mathrm{Mo}$, or their alloys as electrocatalysts for water electrolysis [29,61].

Nickel-based electrocatalysts are an economical and efficient alternative for water electrolysis, they have shown good stability, and electrocatalytic activity for HER and OER $[29,63,66]$. Nickel is a good candidate for electrocatalysts because of its high conductivity, thermal stability, and good electrical properties. Commonly, Ni is a divalent cation, but it can acquire other valences in the range of -1 to +4 . This property gives it the facility to undergo various electronic transitions [66]. To improve the electrocatalytic activity of Ni materials, tuning its chemical environment, structure and morphology is critical [12]. The performance of an electrocatalyst in water electrolysis is modulated by its crystalline structure, chemical composition, hierarchical porosity, size distribution, electrical conductivity, and surface chemistry [66]. Because of this, there has been intensive research in the production of nickel-based electrocatalysts for water electrolysis. 


\subsection{Classification by composition of nickel-based electrocatalysts}

As mentioned before, by modifying the chemical environment of nickel electrocatalysts, the electrocatalytic activity can be improved. In the nickel-based electrocatalysts, a synergistic effect between $\mathrm{Ni}$ and neighboring heteroatoms, like $\mathrm{Fe}, \mathrm{O}, \mathrm{N}$ and $\mathrm{P}$, improves the surface adsorption properties by enhancement of the electronic properties and possibly increments in the surface area [66]. The optimization of nickel electrocatalyst's properties by tuning its composition and crystalline structure can be achieved by cationic and anionic regulation. Cationic regulation involves introducing cations into the structure to regulate the active sites; this is achieved by modifying the free energy of adsorption or desorption. On the other hand, the anionic regulation is the incorporation of anions to regulate the interaction properties and the active sites' reactivity by adjusting its polarization $[66,67]$. A useful tool to predict the activity of a new electrocatalyst is the volcano plot. The volcano plot is constructed based on Sabatier's principle; it states that an optimal electrocatalyst should have an adsorption energy neither too high nor too low with respect to an intermediate in an electrocatalytic reaction. The Volcano plot is obtained by plotting the reaction rate versus the free energy of adsorption of an intermediate $[33,68]$. The volcano plots for HER and OER are shown in Figure 3; even though the descriptors of the reaction rate are different, it can be seen that the best materials for HER and OER are noble metals or their oxides.

To produce economical and efficient electrocatalysts for water electrolysis is essential to develop new materials with tuned compositions, i.e. materials whose surfaces offer precise interactions with the reaction intermediates to promote the electron transfer at the lowest overpotential. For the case of the OER (in acid or alkaline media), the key intermediate adsorbed species are $\mathrm{OH}$ (Eqs. 12 or 17), $\mathrm{O}$ (Eqs. 14 or 18) and $\mathrm{OOH}$ (Eqs. 15 or 19). Nørksov showed that the adsorption energies of these intermediates are linearly related [69]. Ideally, the free energies for each of these processes should be $1.23 \mathrm{eV}$, but these energies correlate according to Eq. 27

$$
\Delta G_{\mathrm{O}}+\Delta G_{\mathrm{OOH}} \approx 3.2 \mathrm{eV}
$$

which implies a theoretical overpotential of $\sim 0.37 \mathrm{~V}$. These linear correlations are known as scaling relationships and reveal reactivity trends in elementary reactions in which related intermediates bind through the same atom or on the same site [70]. These relationships impose limits to the minimum overpotentials required for a process to occur and the maximum catalytic activity that may be obtained [71] Breaking the scaling the limitations imposed by the existence of these scaling relationships would require a bifunctional catalyst capable of dissociating the pathways involved in the mechanism. Song et al. have shown that nanoclusters of $\gamma$-FeOOH added on a $\gamma-\mathrm{NiOOH}$ support act as proton donor/acceptor centers, bypassing the step from $\mathrm{O}$ to $\mathrm{OOH}$, shifting the overpotential below the theoretical limit [72].

In Table 1 some of the most common compositions of nickel-based electrocatalysts are listed with their corresponding general formula, advantages, disadvantages, and examples. 
Table 1. Composition of nickel-based alloys reported in literature.

\begin{tabular}{|c|c|c|c|c|}
\hline $\begin{array}{l}\text { Composition } \\
\text { classification }\end{array}$ & Advantages & Disadvantages & Examples & Ref. \\
\hline $\begin{array}{r}\text { Mono- and } \\
\text { Polymetallic } \\
\text { oxides }\end{array}$ & $\begin{array}{l}\text { - Adjustable structures, } \\
\text { stable in alkaline } \\
\text { electrolyte. } \\
\text { - Transforms to } \\
\text { oxyhydroxides during } \\
\text { OER }\end{array}$ & $\begin{array}{l}\text { - Low conductivity. } \\
\text {-Activity depends } \\
\text { on the metal type, } \\
\text { its oxidation state } \\
\text { and support } \\
\text { electrode. }\end{array}$ & $\begin{array}{r}{ }^{1} \mathrm{LiCo}_{\frac{1}{3}} \mathrm{Ni}_{\frac{1}{3}} \mathrm{Fe}_{\frac{1}{3}} \mathrm{O}_{2} \\
{ }^{1} \mathrm{LaNiO}_{3}\end{array}$ & $\begin{array}{l}{[73]} \\
{[74]}\end{array}$ \\
\hline $\begin{array}{r}\text { Metallic and } \\
\text { bimetallic } \\
\text { embedded or } \\
\text { decorated in } \\
\text { stable host }\end{array}$ & $\begin{array}{l}\text { - Transforms to } \\
\text { oxyhydroxides during } \\
\text { OER. }\end{array}$ & $\begin{array}{l}\text {-Unstable in } \\
\text { extreme acid or } \\
\text { alkaline electrolytes. } \\
\text {-Unstable against } \\
\text { corrosion. }\end{array}$ & ${ }^{1} \mathrm{Co},{ }^{1} \mathrm{NiFe}$ & [75] \\
\hline $\begin{array}{r}\text { Metallic } \\
\text { hydroxides } \\
\text { Bimetallic Het- } \\
\text { erostructures }\end{array}$ & $\begin{array}{l}\text {-Adjustable structure } \\
\text { and composition. } \\
\text { - Transforms to } \\
\text { oxyhydroxides during } \\
\text { OER. }\end{array}$ & $\begin{array}{l}\text {-Unstable at high } \\
\text { positive potentials. }\end{array}$ & $\begin{array}{r}{ }^{3} \mathrm{Fe} \text { Ni hydroxide } \\
{ }^{3} \mathrm{NiFe} \text { LDH-NS@DG10 }\end{array}$ & $\begin{array}{l}{[76]} \\
{[77]}\end{array}$ \\
\hline $\begin{array}{r}\text { Metallic and } \\
\text { bimetallic } \\
\text { oxyhydroxides }\end{array}$ & $\begin{array}{l}\text {-Adjustable structure } \\
\text { and composition. }\end{array}$ & & ${ }^{3} \mathrm{NiOOH}$ & [78] \\
\hline $\begin{array}{l}\text { Chalcogenides. } \\
\text { Sulfur and } \\
\text { selenide based. }\end{array}$ & $\begin{array}{l}\text {-High conductivity. } \\
\text {-Efficient mass transfer. } \\
\text {-High density of active } \\
\text { sites. } \\
\text { - Resistance to } \\
\text { corrosion and } \\
\text { electrolyte poisoning. }\end{array}$ & & $\begin{array}{r}{ }^{1} \mathrm{FeNiS}_{2} \\
{ }^{1}(\mathrm{NiCo})_{0.85} \mathrm{Se} @ \mathrm{NiCoLDH}\end{array}$ & $\begin{array}{l}{[79]} \\
{[80]}\end{array}$ \\
\hline $\begin{array}{r}\text { Metallic and } \\
\text { bimetallic } \\
\text { phosphides }\end{array}$ & $\begin{array}{l}\text {-Adjustable structure } \\
\text { and composition. }\end{array}$ & $\begin{array}{l}\text {-Unstable at high } \\
\text { positive potentials. }\end{array}$ & ${ }^{1} \mathrm{Ni}_{2} \mathrm{P},{ }^{1} \mathrm{Co}_{3} \mathrm{NiP}$ & $\begin{array}{l}{[81]} \\
{[82]}\end{array}$ \\
\hline $\begin{array}{l}\text { Phospho- } \\
\text { chalcogenides }\end{array}$ & $\begin{array}{l}\text {-High electronic } \\
\text { conductivity. } \\
\text {-Adjustable electronic } \\
\text { structure. }\end{array}$ & & ${ }^{3} \mathrm{Ni}_{0.9} \mathrm{Fe}_{0.1} \mathrm{PS}_{3}$ & [8] \\
\hline $\begin{array}{r}\text { Bi- and } \\
\text { trimetallic } \\
\text { Oxyphos- } \\
\text { phides }\end{array}$ & $\begin{array}{l}\text {-Direct synthesis. } \\
\text {-Wide range of } \\
\text { compositions and } \\
\text { morphology. } \\
\text {-Intermetallic synergy. }\end{array}$ & $\begin{array}{l}\text {-Poor performance } \\
\text { in alkaline media. }\end{array}$ & ${ }^{3} \mathrm{FeCo}_{3} \mathrm{Mo}_{3} \mathrm{P}-\mathrm{O}$ & [83] \\
\hline Nitrides & $\begin{array}{l}\text {-High electronic } \\
\text { conductivity. } \\
\text {-Inert in harsh } \\
\text { electrolytes. }\end{array}$ & $\begin{array}{l}\text {-Unstable at long } \\
\text { term experiments. } \\
\text {-Difficult } \\
\text { morphology and } \\
\text { composition } \\
\text { control. }\end{array}$ & ${ }^{1} \mathrm{Ni}_{3} \mathrm{FeN}$ & [84] \\
\hline
\end{tabular}

\begin{tabular}{|c|c|}
\hline NS & D \\
\hline${ }^{1} \mathrm{Fo}$ & ${ }^{2}$ For HER \\
\hline
\end{tabular}




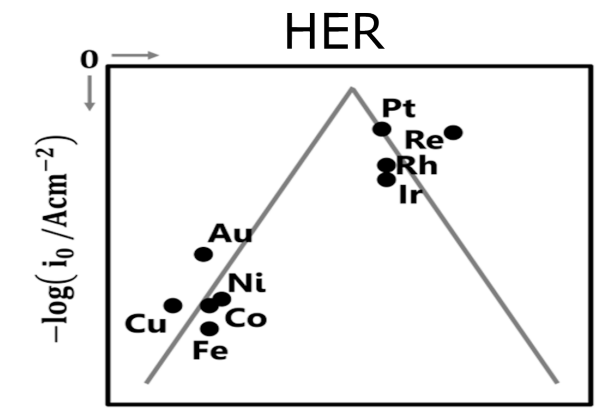

a)

M-H / kcal mol-1

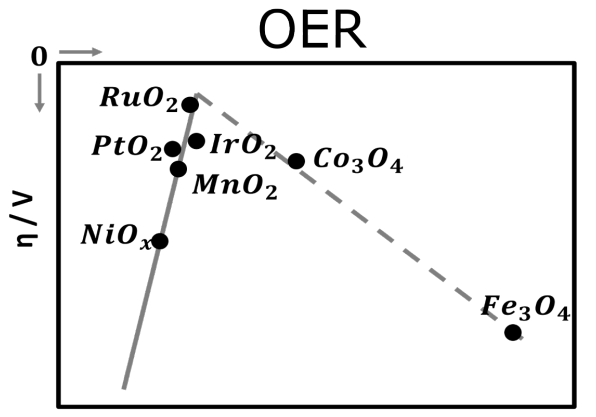

b)

$\Delta H_{*}^{\circ} / \mathrm{kI} \mathrm{mol}^{-1}$

Figure 3. (a) Volcano plot for HER, exchange current density plotted against metal-H binding energy. (b) Volcano plot for OER, overpotential for OER versus the enthalpy of the oxide transition. Modified from [88] and [33], respectively.

Table 1. Composition of nickel-based alloys reported in literature (Continued).

\begin{tabular}{|c|c|c|c|c|}
\hline $\begin{array}{l}\text { Composition } \\
\text { classification }\end{array}$ & Advantages & Disadvantages & Examples & Ref. \\
\hline $\begin{array}{l}\text { Boride het- } \\
\text { erostructures }\end{array}$ & $\begin{array}{l}\bullet \text { High conductivity. } \\
\bullet \text { Corrosion resistance } \\
\text { in acidic and alkaline } \\
\text { media. }\end{array}$ & & ${ }^{2} \mathrm{Ni}_{3} \mathrm{~B} / \mathrm{MoB}$ & [85] \\
\hline $\begin{array}{r}\text { Bimetallic } \\
\text { Phosphates }\end{array}$ & $\begin{array}{l}\text {-Work in neutral and } \\
\text { alkaline electrolytes. } \\
\text {-Adjustable } \\
\text { morphology, facilitating } \\
\text { mass transport and } \\
\text { electron/proton } \\
\text { transfer. } \\
\text { - Long term stability. }\end{array}$ & & ${ }^{3} \mathrm{NiMoPO}_{x}$ & [86] \\
\hline Borates & & $\begin{array}{l}\text {-Work in neutral and } \\
\text { alkaline electrolytes. } \\
\text { Adjustable morphology. } \\
\text {-Stability }\end{array}$ & ${ }^{1} \mathrm{Ni}-\mathrm{B}_{i}$ & [87] \\
\hline
\end{tabular}

\subsection{Structural classification of nickel-based electrocatalysts}

Another alternative to improve electrocatalytic activity is modifying the structure and morphology to increase the number of active sites and shorten the paths for charge or mass transport [63]. Several structures of nickel-based electrocatalyst are presented.

\subsubsection{Perovskite structure}

Perovskites are a type of oxides with the general formula $\mathrm{ABO}_{3}$ (Figure $4 \mathrm{a}$ ), where A represents an alkaline earth element, like $\mathrm{Ca}, \mathrm{Ba}$, and $\mathrm{Sr}$, or a lanthanide element, commonly La or Pr. [15,89] and B represents transitions metals, like Ni, Co or Fe. These usually have oxidation states $+3,+4$, or a mixture of both, depending on the oxidation state of A. B is at the center of the octahedron, and A fills empty spaces to complete the perovskite structure.[15] By partial substitution of atoms of either A or B, it is possible to tune the perovskite structure $\left(\mathrm{A}_{x} \mathrm{~A}^{\prime}{ }_{(1-x)} \mathrm{B}_{y} \mathrm{~B}^{\prime}{ }_{(1-y)} \mathrm{O}_{3}\right)$ to enhance the electrocatalytic activity, modify the chemical stability, the ionic conductivity, the cell parameters or 
a)

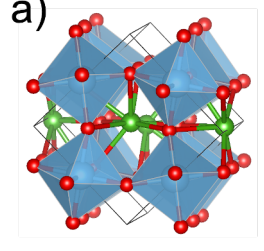

d)

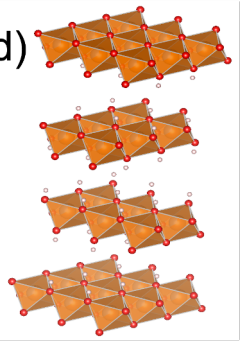

b)

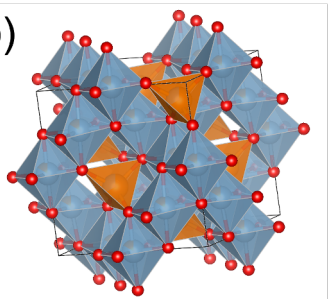

e)

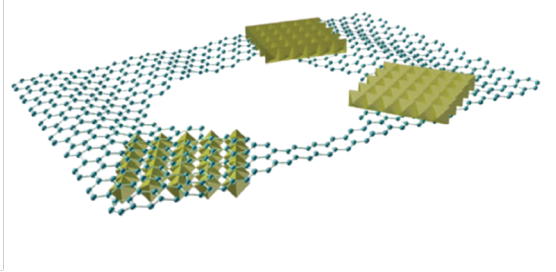

c)

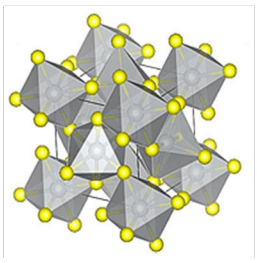

f)

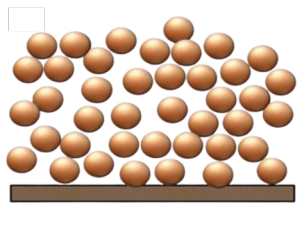

Figure 4. General structure of (a) perovskite, (b) spinel, (c) pyrite [92], (d) layered structure, (e) example of an heterostructure [77], and f) scheme of an amorphous structure. [93]

the thermal properties. $[89,90]$ Park and coworkers evaluated the impact of the partial substitution of the transition metal in perovskites had in electrocatalytic activity for OER. By partial substitution of $\mathrm{Mn}, \mathrm{Fe}$, or $\mathrm{Co}$ in $\mathrm{LaNiO}_{3}$ they observed a general improvement in the OER activity, but the best result was obtained by partial substitution of Fe [90]. Perovskites' ability to stack A and B cations to for ordered layer structures, like double perovskites $\left(\mathrm{AA}^{\prime} \mathrm{BB}^{\prime} \mathrm{O}_{6}\right)$, in which the unit cells is the double of a common unit cell makes it possible to achieve diverse electronics structures and synergistic effect between the cations $[14,91]$.

\subsubsection{Spinel}

Spinel is a binary oxide with the general formula $\mathrm{AB}_{2} \mathrm{O}_{4}$ (Figure 4 b) $[14,94]$. Spinel contains two crystallographic sites, octahedral and tetrahedral, that can lead to two different types of structure depending on where the metals are localized: the normal spinel $\left(\left(\mathrm{A}_{T_{d}}^{2+}\right)\left(\mathrm{B}_{\mathrm{O}_{h}}^{3+}\right)_{2} \mathrm{O}_{4}\right)$ and the inverse spinel $\left(\left(\mathrm{A}_{\mathrm{O}_{h}}^{2+}\right)\left(\mathrm{B}_{T_{d}}^{3+}\right)\left(\mathrm{B}_{\mathrm{O}_{h}}^{3+}\right)_{2} \mathrm{O}_{4}\right)$. [15,95] The main advantages of this structure are the good electric conductivity due to the mixed-valence system, high charge transfer efficiency, and high stability in harsh alkaline electrolyte and under high anodic potentials. Also, the electrocatalytic activity can be modulated by incorporating secondary metals, like Ni, Mn, $\mathrm{Zn}$. [14,15,95,96] Two of the most studied types of spinels are Ferrite $\left(\mathrm{MFe}_{2} \mathrm{O}_{4}\right)$ and Cobaltite $\left(\mathrm{MCo}_{2} \mathrm{O}_{4}\right)[14,15]$. Torres-González et al. reported the application of $\mathrm{NiFe}_{2} \mathrm{O}_{4}$ hollow nanospheres with high surface area and stability as anode material for water electrolysis in an alkaline microfluidic device [97]. Chien et al. produced a $\mathrm{NiCO}_{2} \mathrm{O}_{4}$ aerogel for OER with high surface area and a well-connected 3D and through pore structure that increased the availability of active sites and the easy access of the electrolyte to these sites [98].

\subsubsection{Pyrite}

Pyrite is a common structure of transition metal dichalcogenides $\left(\mathrm{MX}_{2}\right)$, where $\mathrm{M}$ could be $\mathrm{Fe}, \mathrm{Co}$, or Ni, and $\mathrm{X}$ is $\mathrm{S}$ or Se (Figure 4c). Cations are localized inside a sulfur or selenium octahedron $[99,100]$. This structure is characterized by its long-term stability in either acidic or alkaline electrolytes and for synergistic effect between the binary metals [85]. He et al. reported the synthesis of bifunctional electrocatalyst for HER and OER. The $\mathrm{Ni}_{0.33} \mathrm{Co}_{0.67} \mathrm{~S}_{2}$ nanoneedles displayed a superior electrocatalytic activity for both processes that was attributed to the optimized balance from the electron transfer capability, the increased exposure of active sites, and the good dissipation of gaseous products [99]. 


\subsubsection{Layered structures}

The layered structure type oxides, also known as layered double hydroxides (LDH), consist of ionic layers that contain interlayer ions of the opposite charge or water molecules that balance the overall charge and increase the spacing between layers (Figure $4 \mathrm{~d}$ ). The layers have a brucite like structure $[15,101]$. Transition metal hydroxides and oxyhydroxides have this type of structure. These compounds show good electric conductivity and are stable in alkaline electrolytes [15]. Ni-Fe LDHs have been used as a protection layer for silicon photocathodes, and electrocatalyst for HER in alkaline solution, displaying outstanding stability [102]. Single monolayers are produced by liquid exfoliation to increase the electrocatalytic activity of the LDH materials. This treatment increases the number of active sites in the structure's edges, making the inner layer more accessible to the electrolyte, and increases the electronic conductivity [75]. Liang et al. reported the synthesis and chemical exfoliation of NiCo LDH and their activity towards OER and an enhancement in their activity due to the increased surface and more exposed active sites [103].

\subsubsection{Heterostructures}

Heterostructures are hybrid materials comprised of several materials, and in this case, with synergistic effects on the electrocatalysis of water electrolysis [79,104] (Figure 4e). Each component of the heterostructure accelerates one specific rate-determining step of water electrolysis or enhances a chemical or physical property of the electrocatalyst [78]. The interest in developing heterostructures as electrocatalysts resides in the fact that a single material has limited activity towards water splitting because of either low electronic conductivity, insufficient active sites, or instability. Instead, heterostructures have a tuned electronic structure that merges the advantages of different materials to produce an ideal or at least a more efficient electrocatalyst. [104] Zheng et al. reported a core-shell hybrid nanostructure, $\mathrm{Ni}_{3}\left(\mathrm{~S}_{0.25} \mathrm{Se}_{0.75}\right) @ \mathrm{NiOOH}$, on nickel foam as efficient water splitting electrocatalyst. The core was made of nickel chalcogenides, which optimized the electronic structure and the catalytically active nickel oxide/oxyhydroxide shell. This heterostructure harnessed the advantages of both materials and, by a rational design, synthesized an efficient water electrocatalyst [105].

\subsubsection{Amorphous structures}

Electrocatalysts with amorphous structures are solids with randomly arranged atoms and can have different compositions, like oxides, layered double hydroxides (LDH), binary and ternary oxides and chalcogenides, borides, or phosphates $[93,106,107]$ (Figure 4f). The use of amorphous nickel-based electrocatalysts for water electrolysis increases the number of active sites available by incrementing the diffusion of electrolyte to inner parts of the material, the ECSA, and the number of defects [93]. He et al. synthesized an amorphous Ni-based bifunctional catalyst that was stable, and robust in both processes. The electrocatalyst required an oxidative pretreatment for HER in a near-neutral aqueous buffer. For OER, at anodic potentials, the film was converted to nickel oxide reversibly [108]. Trudel et al. developed a photochemical route to synthesize binary $\mathrm{Fe}_{100-y} \mathrm{Ni}_{y} \mathrm{O}_{x}$ and ternary $\mathrm{Fe}_{100-y-z} \mathrm{Co}_{y} \mathrm{Ni}_{z} \mathrm{O}_{x}$ amorphous oxides with highly controlled compositions and homogeneous distribution of metals that show significant improvement in the thermodynamic and catalytic performance toward OER. Based on the behavior of the Tafel slope, onset overpotential, and the overpotential at $10 \mathrm{~mA} \mathrm{~cm}^{-2}$ at different compositions and annealing temperatures, they propose a synergistic effect between $\mathrm{Ni}$ and $\mathrm{Fe}$ and that $\mathrm{Fe}$ and Ni play a specific role in the kinetic and thermodynamic determining steps of the OER mechanism, respectively, suggesting the bifunctional activity of these materials. $[109,110]$ 


\subsection{Structural considerations for nickel-based electrocatalysts}

The electrochemical activity of a material can be tailored by controlling the morphology, crystallinity, size of primary particles, and microstructure $[95,111]$. The ideal electrocatalyst has a big ECSA and accessible and continuous transport channels for charge carrier transport. This feature enables the electrocatalyst to increment the number of active sites available and facilitate the electrolyte access [98]. Definitively, knowing the effect that modifications in the structure of a material can have on its electrocatalytic activity is of great importance.

\subsubsection{Substrate}

Depending on the support used for the deposition or casting of the electrocatalyst, the electrocatalytic activity can be either enhanced or diminished. The correct substrate can increase the loading of electrocatalyst and favor the electron transfer $[63,112]$. Conductive substrates and 3D substrates with open pores have been investigated due to their chemical and physical properties that enhance ionic and electronic conductivity and increase the loading of electrocatalyst $[63,112,113]$. Some disadvantages that can come with using substrates are the poor kinetics of electrocatalytic reactions and low durability. These two aspects are strongly related to the weak catalyst-substrate contact responsible for the electronic resistance, vigorous gas evolution, and the consequent peeling off of the catalyst $[105,114]$. Two substrates that have been widely used to study water electrolysis are carbon-based materials and nickel foam. Carbon-based materials, like graphene and nanotubes, are conductive substrates with high surface area and stability $[63,115,116]$. They provide physical support and a conductive path for charge transport [115]. Nickel foam (NF) is a cheap material that is stable in alkaline media and can function as inert porous support or as a nickel source. The 3D open pore structure favors the mass transfer and the effective bubble release; also, it has high electrical conductivity and a large surface area $[105,113,114]$. Finally, a critical factor favoring the use of NF is the direct growth of active material in the surface of the substrate that enhances the catalyst-surface contact that improves the charge transport [113].

\subsubsection{Surface defects}

The preparation of a perfect crystal without any defect is complex. Many defects can be present in a crystal, like point defects, line defects, plane defects, and volume defects. All of these defects can modify the electronic and surface properties of an electrocatalyst [117]. The absence of specific atoms, doping with heteroatoms, and the lattice's reconstruction break the electron-hole symmetry in the structure $[117,118]$. The defective regions form dangling groups that alter the electronic density and increase the chemical reactivity [118]. Intrinsic defects are beneficial for water electrolysis, as they serve as active sites. However, the induction of defects to a structure commonly involves the use of destructive and corrosive chemical/physical treatment that destroys the microstructure of the electrocatalyst [119].

\subsubsection{Doping}

An electrocatalyst's surface can be altered by introducing foreign elements, leading to improved electrocatalytic activity for water electrolysis[120]. Doping tunes the native electronic structure of a catalytic surface by intentional alloying of semiconducting materials with the controlled presence of impurities $[66,121]$. Swierk et al. evaluated the effect that doping a nickel (oxy)hydroxide structure with iron had on the OER activation energy. The OER activation energy was similar to the activation energy of $\mathrm{IrO}_{2}$ catalyst [49]. Also, Ni can act as a doping agent. It has been reported in the literature that doping electrocatalyst for water electrolysis with $\mathrm{Ni}$ increments the surface area and therefore the active sites and enhances the conductivity, promoting the full utilization of the electrocatalyst $[94,101]$. 


\subsubsection{Porosity}

Porous structures have proven to enhance the electrocatalytic activity of water electrolysis electrocatalysts. An interconnected porous structure promotes the full utilization of the ECSA and generates a continuous passageway for charge carrier transport that improves the catalytic process $[98,111]$. Finally, porosity increases the electrocatalyst's stability by the efficient liberation of evolving gas bubbles and minimizing the damage of the electrode [111].

\subsubsection{Nanostructuring}

Since electrocatalytic reactions occur at the electrode/electrolyte interface, they depend on the electrocatalyst's surface. The implementation of nanostructures increases the ECSA and, therefore, the number of active sites. The smaller the electrocatalyst particle size, the higher the reaction rate for water electrolysis because nanostructures facilitate the release of smaller bubble gas due to the lower contact with the electrocatalyst. Also, there is an increment in the exposure of active sites to the electrolyte $[101,111]$. In the literature, it is widely reported the implementation of nanostructures as electrocatalysts for water electrolysis. Some morphologies studied are core-shell nickel nanoparticles[29,122], hollow structures[111], nanowires [101], and nanosheets [123].

\section{Synthesis of nickel-based electrocatalysts}

So far, in literature, there have been reported many synthesis methods for nickelbased electrocatalysts, like hydrothermal synthesis [73,85], solvothermal synthesis [124], chemical vapor deposition [125], and coprecipitation [126]. However, most of these techniques require the use of shape directing agents and surfactants; they are also timeconsuming and complicated [95]. Otherwise, at the industrial scale, the production of nickel-based electrocatalysts is done by chemical synthesis of powders that are then pasted onto conductive substrates [12]. That is why it is necessary to develop new techniques that allow the production of nickel-based electrocatalyst at an industrial scale and permit the accurate control of composition, structure, and morphology. A comparison of the three most common synthesis techniques for nickel-based electrocatalysts is shown in Table 2. 
Table 2. Common synthesis techniques for nickel-based electrocatalysts.

\begin{tabular}{|c|c|c|c|}
\hline & Electrodeposition & $\begin{array}{l}\text { Hydrothermal } \\
\text { synthesis }\end{array}$ & Coprecipitation \\
\hline Description & $\begin{array}{l}\text { Reduction and deposition } \\
\text { of an ionic species from a } \\
\text { conductive electrode }\end{array}$ & $\begin{array}{l}\text { Synthesis of materials } \\
\text { in an autoclave with } \\
\text { water as catalyst, } \\
\text { temperature above } 100 \\
{ }^{\circ} \mathrm{C} \text { and high pressure }\end{array}$ & $\begin{array}{l}\text { Simultaneous } \\
\text { precipitation of two } \\
\text { metallic precursors } \\
\text { from a liquid } \\
\text { solution }\end{array}$ \\
\hline Variants & $\begin{array}{l}\text { Galvanostatic or } \\
\text { potentiostatic }\end{array}$ & Surfactant-assisted & Precipitation \\
\hline Advantages & $\begin{array}{l}\text {-Direct deposition in } \\
\text { substrate. } \\
\text { - High control of material } \\
\text { properties and morphology. } \\
\text { - Material properties are } \\
\text { tuned by changes in bath } \\
\text { composition, current } \\
\text { density, pulses duration etc. } \\
\text { - No purification required. } \\
\text { - Scalable }\end{array}$ & $\begin{array}{l}\text { - Direct deposition in } \\
\text { substrate. } \\
\text { - High purity. } \\
\text { - Controlled size and } \\
\text { morphology. } \\
\text { - High quality crystals. } \\
\text { - Lower costs of energy, } \\
\text { instrumentation, and } \\
\text { precursors. } \\
\text { - Environmental } \\
\text { benign synthesis. } \\
\text { - Scalable }\end{array}$ & $\begin{array}{l}\text {-It gives } \\
\text { stoichiometric } \\
\text { mixtures with } \\
\text { well-defined phases. } \\
\text { - Crystalline } \\
\text { structure is tuned } \\
\text { by solution } \\
\text { concentration, } \\
\text { precursors, } \\
\text { temperature, and } \\
p H \text {. }\end{array}$ \\
\hline Disadvantages & $\begin{array}{l}\text {-Unwanted blocking of } \\
\text { evolved gas. } \\
\text {-Electrodeposition } \\
\text { proceeds via specific } \\
\text { reactions, difficulty to } \\
\text { standardize the technique. }\end{array}$ & $\begin{array}{l}\text {-It requires high } \\
\text { temperatures and } \\
\text { pressures. }\end{array}$ & $\begin{array}{l}\text {-Independent } \\
\text { precipitation of } \\
\text { components can } \\
\text { occur. } \\
\text {-It requires further } \\
\text { activation treatment }\end{array}$ \\
\hline Examples & $\begin{array}{l}\mathrm{NiFe} / \mathrm{NF}[127], \mathrm{Ni}-\mathrm{S}-\mathrm{Fe} \\
\text { alloy [128] }\end{array}$ & $\begin{array}{l}\mathrm{NiCo}_{2} \mathrm{O}_{4} \text { [129], } \mathrm{NiFe} \\
\mathrm{LDH} / \mathrm{NF}[130]\end{array}$ & $\begin{array}{l}\mathrm{NiCoP} \text { [131], NiFe } \\
\text { [126] }\end{array}$ \\
\hline
\end{tabular}

\subsection{Hydrothermal synthesis of nickel-based electrocatalysts}

Hydrothermal synthesis is a facile and simple chemical method that occurs in water in a sealed pressure vessel, which enables a reaction to take place at both high temperature and pressure [132]. Water can participate in the reaction as a chemical component or a solvent in a hydrothermal process. The crystalline growth under hydrothermal conditions involved [133]: (i) the dissolution of reactants producing ions or molecular groups in the hydrothermal medium; (ii) the ions or molecular groups are diffused to the low-temperature region of the vessel, where the seed crystal is grown to form a supersaturated solution; (iii) the ions or molecular groups are adsorbed, decomposed, and desorbed at the growth interface; (iv) the adsorbed material is transported at the interface promoting the dissolved matter to crystallize to achieve the desired product finally. Several Ni-based electrocatalysts have been synthesis by traditional or variants of hydrothermal methods. For instance, a mesoporous $\mathrm{NiCo}_{2} \mathrm{O}_{4}$ material was synthesized by a combination of templating with hydrothermal synthesis [129]. Studies of the electron transfer kinetics in the OER of $\mathrm{NiCo}_{2} \mathrm{O}_{4}$ showed an improved overpotential of $\sim 350 \mathrm{mV}$, and better long-term stability compared to commercially available $\mathrm{NiCo}_{2} \mathrm{O}_{4}$ [129]. In another work, Liu et. al. synthesized single-crystalline NiFe LDH by the fluoride-assisted hydrothermal method [130]. It was demonstrated that the NiFe LDH possessed higher 
activity for the OER than the well-known $\mathrm{RuO}_{2}$ exhibiting an ultra-small cell voltage of $1.52 \mathrm{~V}$ at a current density of $20 \mathrm{~mA} \mathrm{~cm}^{-2}$ at room temperature, as well as good long-term stability [130]. More recently, $\mathrm{Ni}_{2} \mathrm{P}$ nanowires were synthesized through a one-step hydrothermal approach, in which water, red phosphorus, nickel acetate, and hexadecyl trimethyl ammonium bromide were used as the solvent, phosphorous and nickel sources, and active agent, respectively [134]. The $\mathrm{Ni}_{2} \mathrm{P}$ nanowires were applied as electrocatalysts for HER and OER.The overpotential was $320 \mathrm{mV}$ and the Tafel slope was $73 \mathrm{mV} \mathrm{dec}^{-1}$ for HER. Meanwhile, the $\mathrm{Ni}_{2} \mathrm{P}$ nanowires showed an electrocatalytic OER activity with an overpotential of $1.51 \mathrm{~V}$ (vs. RHE) and Tafel slope of $46 \mathrm{mV} \mathrm{dec}^{-1}$. Overall, these examples demonstrated the versatility of the hydrothermal method in the synthesis of Ni-based electrocatalysts for highly efficient water splitting.

\subsection{Coprecipitation synthesis of nickel-based electrocatalysts}

Coprecipitation refers to the simultaneous precipitation of two metallic precursors from a common liquid solution. Due to its relative simplicity, cost-effective and fast process, the coprecipitation method is considered one of the most applied strategies in the production of nanomaterials in large-scales [135]. The mechanism of homogeneous precipitation involves the separation of the nucleation and growth of the nuclei. In this process, two steps are involved: (i) a short burst of nucleation when the concentration of the precursor species reaches critical supersaturation and (ii) a subsequent slow growth of the nuclei by diffusion of the solutes to the surface on the crystal [136]. Ni-based electrocatalysts have been synthesized using this strategy. For example, NiFe nanocubes having an average side length of $\sim 320 \mathrm{~nm}$ were synthesized following a precipitation method, in which sodium citrate dihydrate acted as a chelating ligand to control the nucleation rate and crystal growth [126]. The NiFe nanocubes were used as bifunctional electrocatalysts for overall water-splitting, demonstrating overpotentials of 271 and $197 \mathrm{mV}$ for OER and HER, respectively, in $1 \mathrm{M} \mathrm{KOH}$ at $10 \mathrm{~mA} \mathrm{~cm}^{-2}$ [126]. In another example, NiCoP nanosheets arrays were synthesized via a urea precipitation method followed by phosphorization [131]. For cathodic HER performance, the NiCoP electrode showed an overpotential of $\sim 133 \mathrm{mV}$ to reach a current density of $50 \mathrm{~mA} \mathrm{~cm}^{-2}$. When used as an OER catalyst, this nanomaterial provides a current density of $50 \mathrm{~mA} \mathrm{~cm}^{-2}$ at an overpotential of $308 \mathrm{mV}$. Moreover, an alkaline electrolyzer requiring a potential of $\sim 1.77 \mathrm{~V}$ to achieve a current density of $50 \mathrm{~mA} \mathrm{~cm}^{-2}$ was fabricated by using NiCoP nanosheets as both OER, and HER electrocatalysts [131].

\subsection{Electrochemical synthesis of nickel-based electrocatalysts}

Electrolytic deposition or electrodeposition is a technique that consists of the reduction or deposition of an electrically conductive species in a conductive electrode by the application of electrical current, the soluble form of the metal to be deposited is present in the electrolyte. The total amount of metal deposited is proportional to the amount of charge passed during the reaction, thus, to the thickness of the layer deposited. The electrodeposition conditions greatly influence the morphology of the product. Some factors that can affect the type of deposit obtained and its quality are: the $p \mathrm{H}$, the presence of contaminants, the crystal planes of the substrate side reactions, and current distribution [137]. The mechanism of electrodeposition consists of four main stages: (i) nucleation, (ii) growth of nuclei, (iii) coalescence, and (iv) layer growth. First, the nucleation process is the formation of new sites or nuclei, and it can be outward (2D) or upward (3D), depending on the strength of the interaction with the substrate. For the nuclei to be stable, they must reach a critical dimension that depends on the overpotential applied to the system. Depending on the reaction rate, the nucleation can be instantaneous or progressive. The rate of nucleation determines the morphology of the final deposit. At high overpotentials, fine crystal grains are obtained; In instantaneous nucleation, the nuclei's growth starts when the nucleation ends. Progressive 


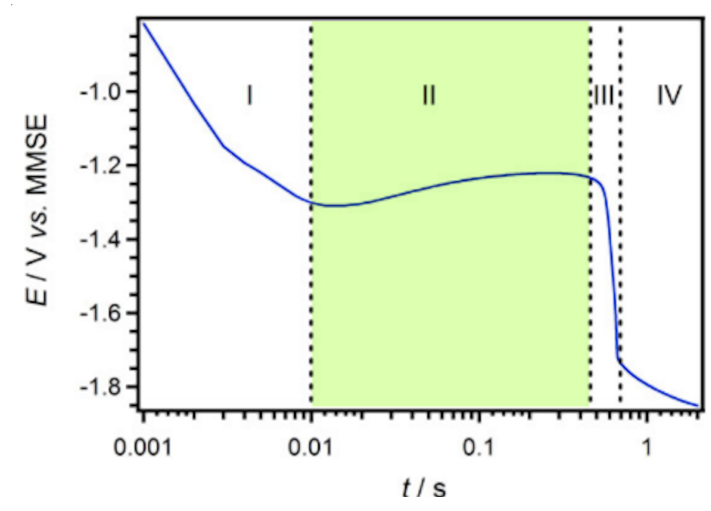

Figure 5. Polarization curve for the galvanostatic deposition of nickel on a gold electrode. Retrieved from [141].

nucleation takes place when lower overpotential values are applied, producing deposits with larger grains and fewer nuclei; the growth occurs simultaneously [137]. According to the controlled parameter, electrodeposition can be potentiostatic or galvanostatic $[138,139]$. When comparing galvanostatic deposition with potentiostatic deposition, it has been demonstrated that the first one produces smaller particle sizes with a better dispersion [140]. Salinas-Quezada et al. describe the potential behavior during galvanostatic electrodeposition of nickel in four regimens: (i) nickel nucleation, (ii) nickel growth, (iii) deposition termination due to local changes in $p \mathrm{H}$, (iv) water reduction [141] (Figure 5). Additionally, they observed a dependency between the deposition current applied and the electrocatalytic activity of nickel films. When lower deposition current values were applied, 22-33 $\mu \mathrm{A}$, the electrocatalytic activity favored methanol oxidation, and with higher deposition currents, 38-66 $\mu \mathrm{A}$, OER was favored, attributed to changes in the growth regime because the geometric area defines the diffusion field of metallic ions during this phase. Indeed, the electrochemical activity of nickel-based electrocatalyst produced by electrodeposition is influenced by the synthesis conditions and the mechanism.

\subsection{Nickel-based electrocatalysts electrodeposition mechanism}

In literature, two types of deposition mechanisms have been reported: (i) normal co-deposition and (ii) anomalous co-deposition. Depending on the type of deposition mechanism, the chemical and physical properties of the deposit can change [142]. The general deposition mechanism for metals of the iron group, fourth period of the periodic table, is shown below (28-30). The rate-limiting reaction is (28) due to the scarcity of adsorption sites for $\mathrm{MOH}^{+}$. [142,143]

$$
\begin{aligned}
\mathrm{M}^{2+}+\mathrm{OH}^{-} & \rightarrow \mathrm{MOH}^{+} \\
\mathrm{MOH}^{+}+\overline{\mathrm{e}} & \rightarrow \mathrm{MOH}_{\mathrm{ad}} \\
\mathrm{MOH}_{\mathrm{ad}}+\overline{\mathrm{e}} & \rightarrow \mathrm{M}+\mathrm{OH}^{-}
\end{aligned}
$$

The main deposition mechanism of bimetallic nickel films is the anomalous co-deposition, in which the bath prefers the deposition of the least noble metal [144-146]. Two factors that could lead to the preferential deposition of the least noble metal are the suppression of the hydroxide intermediate of the more noble metal by the hydroxide intermediate of the least noble and the difference in the dissociation constants between $\mathrm{M}_{1} \mathrm{OH}^{+}$and $\mathrm{M}_{2} \mathrm{OH}^{+}$. These factors result in the higher concentration of hydroxide intermediates of the least noble metal and the saturation of the adsorption sites only by the least noble metal, inhibiting the adsorption of the other metallic species [142]. The main factors that alter the deposition process are: 
- $\quad$ The $p \mathrm{H}$ [142]: high values of $p \mathrm{H}$ favor anomalous deposition.

- The supporting electrolyte $[142,143]$ : the supporting electrolyte commonly contains metallic sulfates and chlorides. Chloride salts favor the normal deposition due to the formation of the chloride intermediate $(\mathrm{MCl})$ that has a faster deposition process than $\mathrm{MOH}^{+}$.

- $\quad$ The buffer capacity of the solution [142]: Sulfate salts can act as a buffer during the deposition process when the electrolyte has a $p \mathrm{H}$ around 2, resulting in normal deposition.

- $\quad$ The working cycle [142]: during pulsed working cycles, the normal mechanism is favored due to delay in $\mathrm{pH}$ changes.

- $\quad$ Electrolyte degradation $[147,148]$ : the degradation of the electrolyte can cause self-termination of the deposition process altering the structure, morphology, and chemical composition of the deposit.

\section{Nickel-based electrocatalysts for water electrolysis}

As previously mentioned, $\mathrm{H}_{2}$ production by water electrolysis is an ideal alternative for energy storage compared to the reforming process as it does not generate byproducts harmful to the environment and allows the use of intermittent energies. Nickel-based electrocatalysts are ideal for water electrolysis due to their earth abundance and low cost. These materials have proven to efficiently catalyze OER [12,103,124,149]. HER $[8,85,131,150,151]$ and overall water electrolysis [126] electrocatalysts are being studied. Table 3 compares nickel-based electrocatalysts' performance parameters for OER and HER in alkaline, acid, and neutral electrolytes. All the electrocatalysts listed in Table 3 and Table 4 were considered for the comprehensive study of nickel-based electrocatalysts for water electrolysis in the present work, but not all of them are discussed in the following sections.

\subsection{Nickel-based electrocatalysts for $O E R$}

Nickel oxides [95,155], and hydroxides $\left(\mathrm{Ni}(\mathrm{OH})_{2}\right)[10,157]$ have been widely investigated for their outstanding performance in OER. $\mathrm{Ni}(\mathrm{OH})_{2}$ can be found in two phases, $\alpha-\mathrm{Ni}(\mathrm{OH})_{2}$ and $\beta-\mathrm{Ni}(\mathrm{OH})_{2}$, and by a quasi-reversible redox process, they can transform to $\gamma-\mathrm{NiOOH}$ and $\beta-\mathrm{NiOOH}$, respectively[10] (Figure 6). $\gamma-\mathrm{NiOOH}$ and $\beta$ $\mathrm{NiOOH}$ differ in the interlaying species and the oxidation state of nickel. $\beta-\mathrm{NiOOH}$ is an ordered structure, with protons between layers, $d$-pacing of $4.6 \AA$, and a nickel trivalent oxidation state $\left(\mathrm{Ni}^{\mathrm{III}}\right) \cdot \gamma-\mathrm{NiOOH}$ is a hydrated structure with interlayer water molecules, and alkali ions, a $d$-spacing of $7 \AA$ and a nickel oxidation state larger than +3 [15]. Despite the extensive research for the development of nickel-based electrocatalyst for water electrolysis, the mechanism of water electrolysis in nickel-based materials remains unclear. To accurately design a Ni-based electrocatalyst for OER, knowing the active sites and the role of the heteroatoms is critical. The active phase in Ni-based materials has not been clearly identified; $\beta-\mathrm{NiOOH}$ and $\gamma-\mathrm{NiOOH}$ have been identified as the active forms. Louie and Bell [155] compared the OER activity of as-deposited and aged Ni film and Ni-Fe oxide films. They concluded that (1) a mixture of ordered and disordered $\beta-\mathrm{NiOOH}$ were responsible for the high performance, and (2) that the aging process increases the electrocatalytic activity of pure Ni films $\left(m_{T}=42 \mathrm{mV} \mathrm{dec}-1\right)$, making it comparable to NiFe films with $40 \%$ of Fe $\left(m_{T}=35 \mathrm{mV} \mathrm{dec}^{-1}\right)$ (Figure 7).

Later, Bediako et al., through an anodization pre-treatment, evaluated the activity, structural changes, and oxidation states of the different phases of $\mathrm{Ni}$ in nickel borate (Ni-B) [158]. After applying a potential of $1 \mathrm{~V}$, the anodized material had an oxidation state of 3.6, associated with $\mathrm{Ni}^{\mathrm{IV}}$ in $\gamma-\mathrm{NiOOH}$, and the non-anodized material had an oxidation state of 3.1 , related to $\mathrm{Ni}^{\mathrm{III}}$ in $\beta-\mathrm{NiOOH}$. The electrocatalytic activity increments with anodization were attributed to the phase conversion from $\beta-\mathrm{NiOOH}$ to $\gamma-\mathrm{NiOOH}$, and the consequent increase of $\mathrm{Ni}^{\mathrm{IV}}$ sites and interlayer space. Gao et al. compared 
Table 3: Performance parameters of nickel-based electrocatalysts for OER in alkaline media.

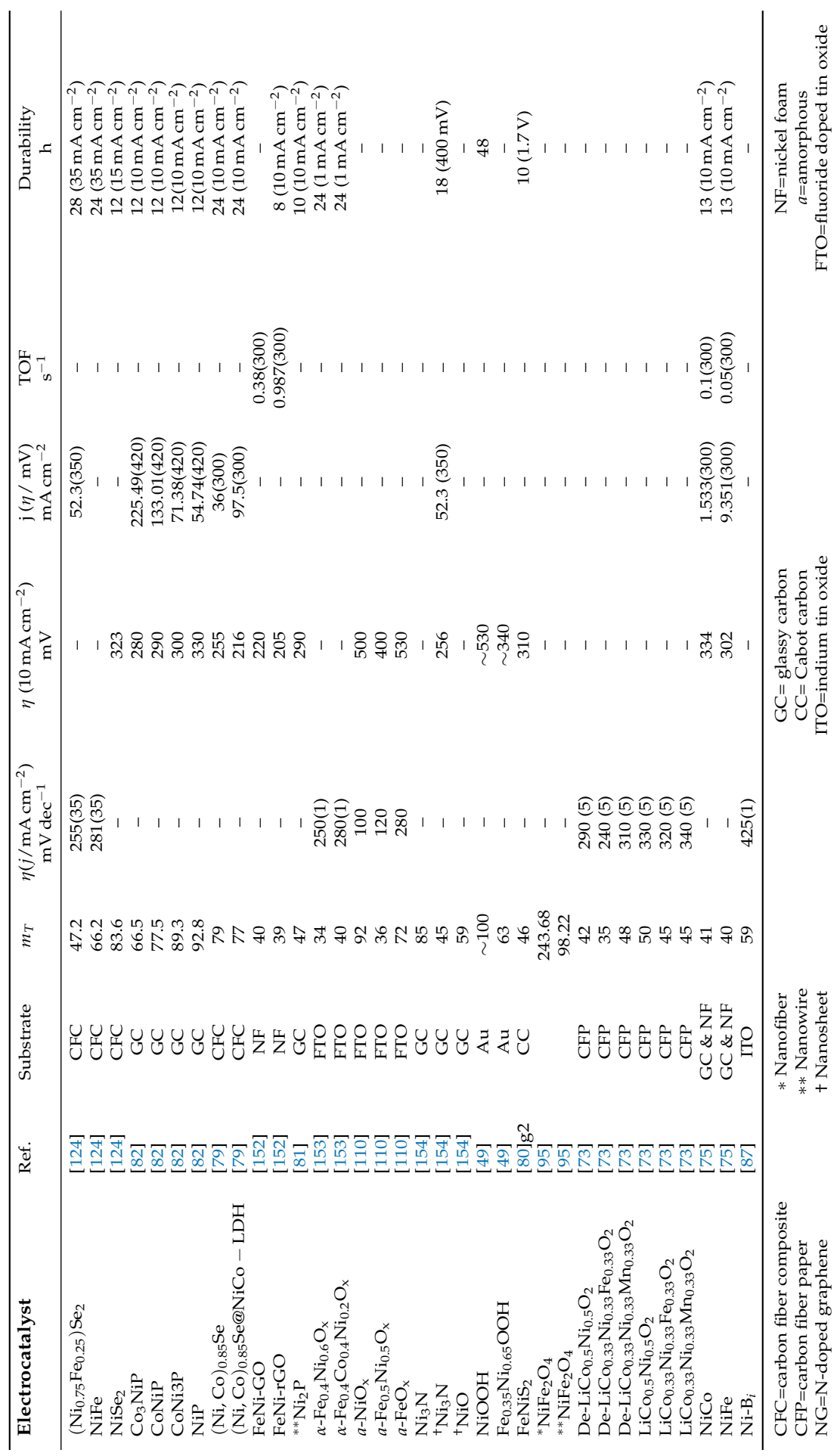


Table 4: Performance parameters of nickel-based electrocatalysts for OER and HER.

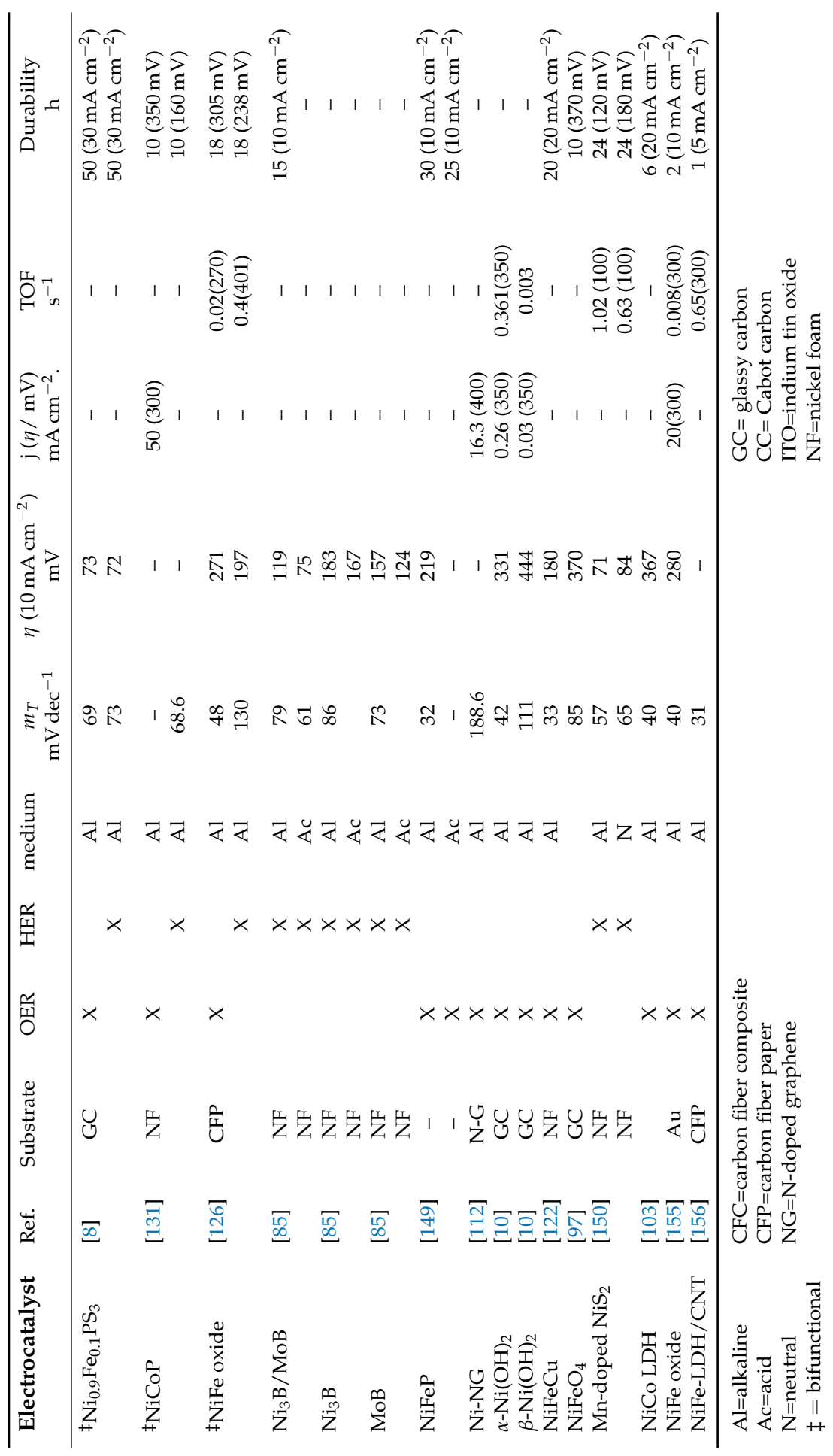




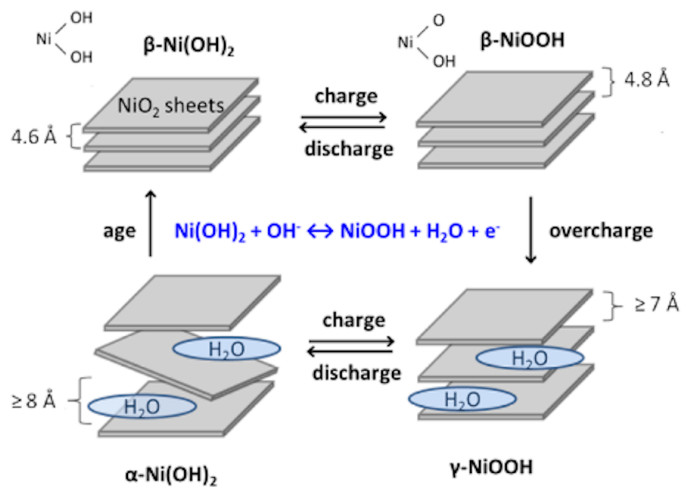

Figure 6. Description of the redox transformation of $\mathrm{Ni}(\mathrm{OH})_{2} / \mathrm{NiOOH}$. Retrieved from [157].

a)

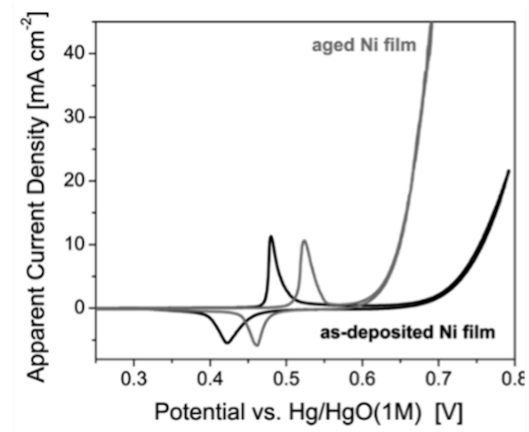

b)

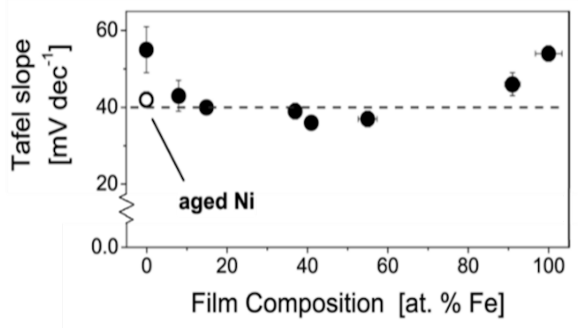

Figure 7. (a) Cyclic voltammograms of as-deposited Ni film and aged Ni film. (b) Tafel slopes for the different compositions of Ni-Fe oxide films. Modified from [155].

$\alpha-\mathrm{Ni}(\mathrm{OH})_{2}$ spheres and $\beta-\mathrm{Ni}(\mathrm{OH})_{2}$ plates electrocatalytic activity for OER. $\alpha-\mathrm{Ni}(\mathrm{OH})_{2}$ spheres were the most active in an alkaline electrolyte (Table 3) [10], attributed to the insitu formation of $\gamma-\mathrm{NiOOH}$, the nickel oxidation state facilitated the formation of $\mathrm{NiOOH}$ and the production of $\mathrm{O}_{2}$. Finally, high stability was displayed by $\alpha-\mathrm{Ni}(\mathrm{OH})_{2}$ spheres. After an increase in activity at 100 cycles, it remained stable until 500 cycles (Figure 8a). In contrast, although $\beta-\mathrm{Ni}(\mathrm{OH})_{2}$ also displayed an increase in activity at 100 cycles, it dramatically dropped at 500 cycles (Figure 8b). To address this discrepancy, Trotochaud et al. studied the effect of electrolyte impurities in OER activity, and specifically, Fe impurities [159]. In the presence of Fe impurities, a 30-fold increase in conductivity and a partial charge transfer effect were observed; these led to an increase in Ni activity. He stated that the aging of nickel-based electrodes leads to incorporating Fe impurities that enhance the catalytic activity of $\beta-\mathrm{NiOOH}$ reported in the literature. Thus, to accurately determine the active phase of $\mathrm{NiOOH}$ is necessary to discard any possible interference.

The effect that unintentional and intentional addition of Fe has in the electrocatalytic activity of Ni-based materials has been reported [159,160]. Axmann et al., using Mössbauer spectroscopy, described nickel-iron hydroxide as a cluster of $\mathrm{Fe}^{\mathrm{IV}} \mathrm{O}_{6}$ octahedra surrounded by six $\mathrm{Ni}^{\mathrm{IV}} \mathrm{O}_{6}$ octahedra, all together form discrete $\mathrm{M}^{4+}$ domains in the LDH structure, that are considered the electroactive sites [160]. Then, Ahn and Bard confirmed the presence of $\mathrm{Ni}^{\mathrm{IV}}$ and $\mathrm{Fe}^{\mathrm{IV}}$ in $\mathrm{NiFeOOH}$ by the implementation of surface interrogation scanning electrochemical microscopy [161]. By the determination of pseudo-first-order OER rate constants, they observed that proceeded via two catalytic sites, one with "fast" kinetics $\left(k=1.70 \mathrm{~s}^{-1}\right)$ and other with "slow" kinetics $\left(k=0.04 \mathrm{~s}^{-1}\right)$ for $\mathrm{Ni}_{0.82} \mathrm{Fe}_{0.18} \mathrm{OOH}$, the optimal composition. With a Fe content bigger than $25 \%$ uncontrolled segregation was observed, and the rate of reaction decreased $\left(k=0.34 \mathrm{~s}^{-1}\right)$. The "fast" active site was attributed to $\mathrm{Fe}^{\mathrm{IV}}$ sites due to the match of the fraction of "fast" sites $(17.6 \%)$ and Fe content $(18.19 \%)$. The "slow" active site was attributed to Ni due to 
a) $\alpha-\mathrm{Ni}(\mathrm{OH})_{2}$

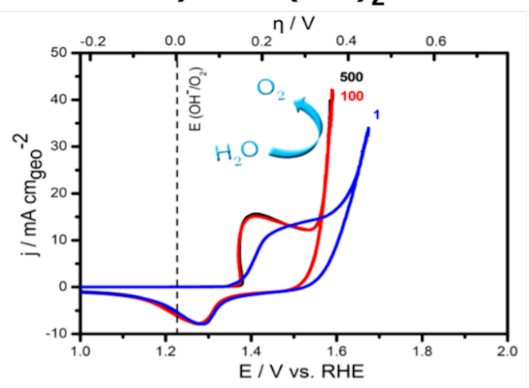

b) $\beta-\mathrm{Ni}(\mathrm{OH})_{2}$

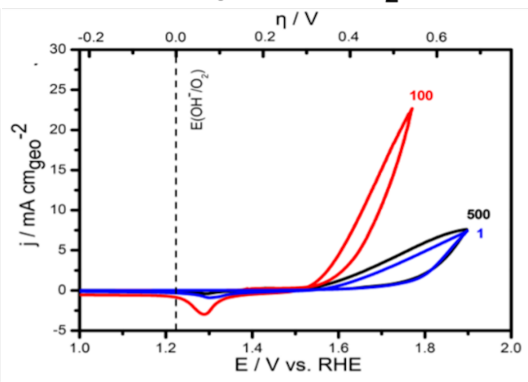

Figure 8. Comparison of cyclic voltammograms after 1, 100 and 500 cycles in $\mathrm{KOH} 1 \mathrm{M}$ for a) $\alpha-\mathrm{Ni}(\mathrm{OH})_{2}$, and b) $\beta-\mathrm{Ni}(\mathrm{OH})_{2}$. Modified from [10].

a

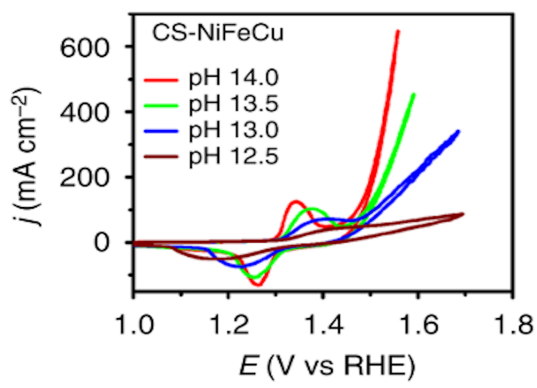

b

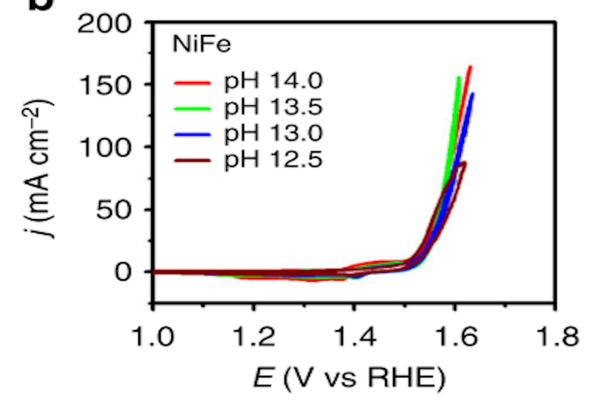

Figure 9. Comparison of $\mathrm{pH}$ dependent OER activity of (a) core shell $\mathrm{NiFeCu}$ and (b) $\mathrm{NiFe}$. Modified from [122].

the similarity of the rate constant with $\mathrm{NiOOH}\left(0.04 \mathrm{~s}^{-1}\right)$. Contrastingly, by a theoretical study with density functional theory (DFT) and its variants, Martinez et al. studied the mechanism of OER in Fe-doped $\mathrm{NiOOH}, \beta-\mathrm{NiOOH}$ was considered the active phase [162]. They stated that (1) the oxidation of superficial $\mathrm{Fe}^{3+}$ to $\mathrm{Fe}^{4+}$, (2) $\mathrm{Fe}^{4+}$ stabilization by oxo moieties, and (3) the ability of $\mathrm{Ni}^{3+}$ to be reduced to $\mathrm{Ni}^{2+}$ had a synergistic effect that enhanced OER electrocatalysis. Independently of how Fe was incorporated, there is an increment in the electrocatalytic activity of Ni-based materials with the addition of $\mathrm{Fe}$, but the active sites have not been clearly elucidated. As stated above, transition metal doping of Ni-based materials cause atomic distortions and defects, increasing the exposure of active sites, modulating the free energy of adsorption of intermediates, and enhancing water dissociation $[150,163]$. By electrodeposition and following dealloying and oxidation treatment, Zhang et al. produced core-shell NiFeCu metal/metal oxide nanoparticles (NP) with high electrical conductivity, and large surface area optimal for OER in alkaline media [122]. Cu was related with the increase in ECSA, the optimal ratio was 10:1:21 (Ni:Fe:Cu) with a $C_{D L}$ value of $54.24 \mathrm{mF} \mathrm{cm}^{-2}$, but the increase in $\mathrm{Cu}$ concentration led to a friable and loose structure. Fe modulated the activity, the optimal concentration of $\mathrm{Fe}^{3+}$ ions was $25 \mathrm{mM}\left(m_{T}=33 \mathrm{mV} \mathrm{dec}^{-1}\right)$. The trimetallic core-shell NP showed a dependency on the electrolyte $p \mathrm{H}$, indicating that non-concerted protonelectron transfers took place during OER (Figure 9). The dependence of electrocatalytic activity with $p \mathrm{H}$ is correlated to the deprotonation of $\mathrm{NiOOH}$ to produce $\mathrm{NiOO}^{-}$a key OER intermediate [164]. Doping $\mathrm{NiO}_{x} \mathrm{H}_{y}$ alters the structural evolution of the electrocatalyst during OER. Dette et al. studied the structural evolution of $\mathrm{NiO}_{x} \mathrm{H}_{y}$ nanosheets (NS), $\mathrm{CoO}_{x} \mathrm{H}_{y}$ NS their alloys and $\mathrm{Ni}_{0.8} \mathrm{Fe}_{0.2} \mathrm{O}_{x} \mathrm{H}_{x}$ NS. The major structural changes were observed with $\geq 40 \%$ of nickel after $200 \mathrm{CV}$ cycles, they cracked or broke apart due to changes in lattice parameters, occasioned by changes in the Ni-Ni distance, from $3.12 \AA$ in $\mathrm{Ni}(\mathrm{OH})_{2}$ to $2.86 \AA$ in $\mathrm{NiOOH}$ (Figure $10 \mathrm{~d}$ ). Nanosheets with $\geq 80 \%$ of Co and 

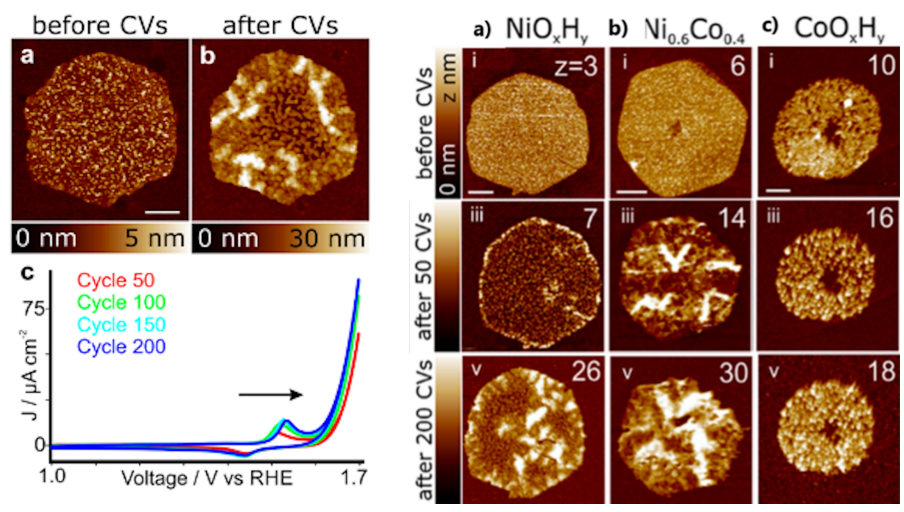

Figure 10. AFM topographical image of $\mathrm{Ni}_{0.8} \mathrm{Fe}_{0.2} \mathrm{O}_{x} \mathrm{H}_{x}$ before cyclic voltammetry (a) and after 200 cycles. (c) Cyclic voltammograms of $\mathrm{Ni}_{0.8} \mathrm{Fe}_{0.2} \mathrm{O}_{x} \mathrm{H}_{x}$ at each stage. (d) AFM topographical images of $\mathrm{NiCoO}_{x} \mathrm{H}_{y}$ nanosheets with different compositions before cyclic voltammetry, after 50 cycles and 200 cycles. Modified from [165]

$\mathrm{Ni}_{0.8} \mathrm{Fe}_{0.2} \mathrm{O}_{x} \mathrm{H}_{x}$ NS (Figure 10a) did not crack after the 200 cycles and maintained their shape with a slight increase in roughness. This was attributed to the higher porosity of the initial structure that allowed the accommodation of strain due to changes in metalmetal distances. Also, $\mathrm{Ni}^{\mathrm{II}} / \mathrm{Ni}^{\mathrm{III}}$ redox peak in the voltammogram shifted: cathodic shift for Co NS and anodic shift for $\mathrm{Ni}_{0.8} \mathrm{Fe}_{0.2} \mathrm{O}_{x} \mathrm{H}_{x}$ (Figure 10c). Accordingly, doping of Ni-based materials can lead to an improvement in their electrocatalytic activity and stability of the electrocatalysts towards OER, tuning electronic and structural properties. $\mathrm{Ni}$ can also serve as a doping agent. Doping $\mathrm{Co}_{0.85}$ Se nanotubes (NT) with $\mathrm{Ni}$ and the electrodeposition of mesoporous NiCo-LDH NS in their surface produced a highly electroactive heterostructure for OER [79]. Ni as a doping agent increased the electrical conductivity, the defect concentration, and, therefore, the number of active sites exposed to the electrolyte due to a non-stochiometric composition. Also, an increase in superficial hydroxy groups $(-\mathrm{OH})$ that enhanced ion permeability was observed in $(\mathrm{Ni}, \mathrm{Co})_{0.85} \mathrm{Se}$ $(85.45 \%)$ compared to undoped $\mathrm{Co}_{0.85} \mathrm{Se}(80.54 \%)$. Ni and Co were considered the active sites. This heterostructure had an excellent electrocatalytic activity and stability (Table 3 ) due to the porous structure and synergistic relation between the insulating NiCo-LDH and the metallic $(\mathrm{Ni}, \mathrm{Co})_{0.85} \mathrm{Se}$. Introducing an anion to form a salt is an alternative and efficient complementary strategy for the improvement of Ni-based materials for OER electrocatalysis. Wang evaluated the effect of selenylation in the electrocatalytic activity of Ni and NiFe NS synthesized by hydrothermal treatment over carbon fiber cloth [124]. $\left(\mathrm{Ni}_{0.75} \mathrm{Fe}_{0.25}\right) \mathrm{Se}_{2}$ displayed an efficient activity for OER (Table 3). Upon selenylation, redox peak attributed to $\mathrm{Ni}^{\mathrm{II}} / \mathrm{Ni}^{\mathrm{III}}$ in $\mathrm{NiS}_{2}$ voltammogram shifted to $1.39 \mathrm{~V}$ $(\mathrm{Ni}$ precursor $=1.42 \mathrm{~V})$, and in $\left(\mathrm{Ni}_{0.75} \mathrm{Fe}_{0.25}\right) \mathrm{Se}_{2}$ shifted to $1.45 \mathrm{~V}(\mathrm{NiFe}$ precursor $=1.47 \mathrm{~V})$. This shift was attributed to the stronger charge transfer after selenylation due to low polarization. Even though both materials shifted to negative values, $\left(\mathrm{Ni}_{0.75} \mathrm{Fe}_{0.25}\right) \mathrm{Se}_{2}$ redox peak position was more positive, indicating that oxidation of $\mathrm{Ni}^{2+}$ to $\mathrm{Ni}^{3+}$ requires more energy, which tends to favor OER. To further enhance the electrocatalytic activity of Ni-based materials, treatments previous to the OER electrocatalysis have been implemented, like anodization [10], dealloying [122], oxidation [122] and exfoliation [75]. Exfoliation of bulk NiFe LDH, NiCo LDH, and CoCo LDH facilitated electron transport on single-layer nanosheets than in bulk LDH. Exfoliation reduces the size of the layers, increasing the ECSA and edges' length. Edges have open coordination sites that act as catalytic sites. They found that the electrocatalytic activity for exfoliated and bulk LDH was $\mathrm{NiFe}>\mathrm{NiCo}>\mathrm{CoCo}$. 


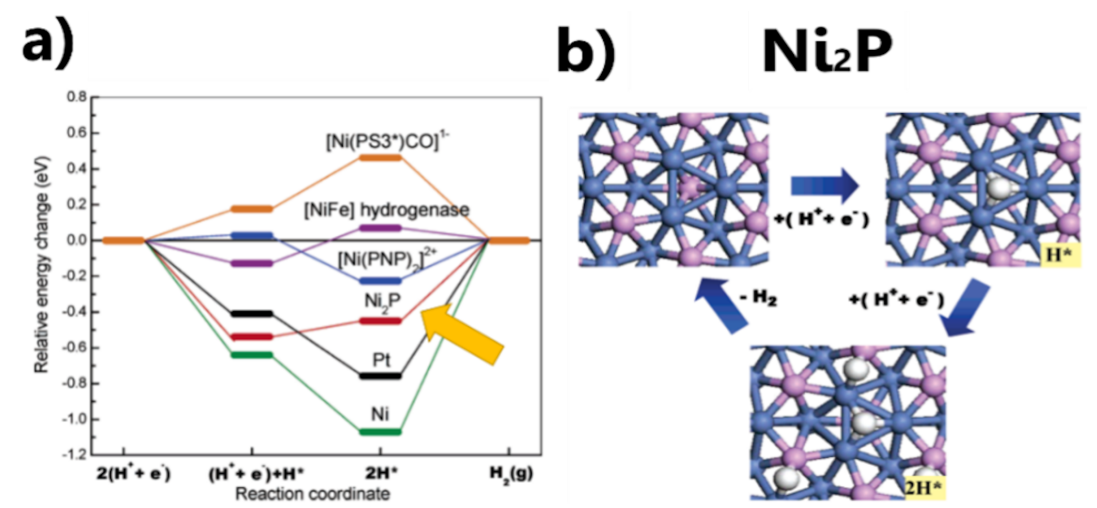

Figure 11. (a) Relative energy changes for HER. (b) HER mechanism in $\mathrm{Ni}_{2} \mathrm{P}$ surface. Modified from [166].

\subsection{Nickel-based electrocatalysts for HER}

Up to date, there is no agreement about the HER mechanism in Ni-based electrocatalysts [12]. The theoretical study of the HER mechanism helps to identify and study active sites and to develop a path for the efficient synthesis of HER electrocatalysts. An ideal HER electrocatalyst must strongly trap $\mathrm{H}$ atoms and desorb molecular $\mathrm{H}_{2}$ easily. If it is not the case, doping should help tune the metal-H bond strength to facilitate the (1) $\mathrm{H}^{+}$adsorption, (2) $\mathrm{H}^{+}$reduction, and (3) the formation of $\mathrm{H}_{2}$ and its desorption. Liu et al. by Density Functional Theory (DFT) described the high electrocatalytic performance of $\mathrm{Ni}_{2} \mathrm{P}$ by comparing the relative energy change for each step of HER mechanism of this material with $[\mathrm{NiFe}]$ hydrogenase, $\mathrm{Pt}^{\mathrm{III}}$ and $\mathrm{Ni}^{\mathrm{III}}$ (Figure 11a). $\mathrm{Ni}_{2} \mathrm{P}$ had energy changes nearer to 0 than $\mathrm{Ni}^{\mathrm{III}}$ and $\mathrm{Pt}^{\mathrm{III}}$ in the second step; this gave an insight into the $\mathrm{Ni}_{2} \mathrm{P}$ favorable kinetics for HER. Even though a poisoning effect of $\mathrm{Ni}$ sites due to the strong bonding of $\mathrm{Ni}-\mathrm{H}$ was identified, this phenomenon, far from decreasing the HER catalysis, enhanced the electrocatalytic activity of $\mathrm{Ni}_{2} \mathrm{P}$, as it favors the occurrence of HER in the Ni-P bridges (Figure 11b) [166].

In another theoretical study for HER by DFT, Greeley et al., screened pure metals and their alloys to determine highly active compositions for HER. The study was done by comparing the free energy of hydrogen adsorption $\Delta G_{H}$ of each material [167].

Combining theoretical and experimental studies can lead to the design of a highly efficient HER electrocatalyst. Man et al. evaluated the effect that Fe $\left(d^{6}\right)$, Co $\left(d^{7}\right), \mathrm{Mn}$ $\left(d^{8}\right)$, and Mo $\left(d^{9}\right)$ have in $\mathrm{NiP}\left(\mathrm{Ni}\left(d^{10}\right)\right)$ by theoretical and experimental methods. The electrocatalysts were synthesized by wet-chemistry and the electrode by drop-casting the catalyst ink into glassy carbon. [168] They concluded that the addition of transition metals with $d$-electron deficiencies enables the electron delocalization and, therefore, the modification of the electronic structure and the hydrogen adsorption energy. However, the efficiency of the electrocatalyst depended on the $\mathrm{H}$ coverage. For low and high coverage Mo and $\mathrm{Co}$, were the most efficient doping agents (Figure 12a-c). NiMoP required an $\eta$ of $400 \mathrm{mV}$ at a current density of $10 \mathrm{~mA} \mathrm{~cm}^{-2}$, which indicates a high electron mobility because Mo presents the biggest $d$-electron deficiency (Figure 12c). To further investigate the mechanism of HER, the relationship between doping, structure, and electrocatalytic activity must be evaluated. $\mathrm{NiS}_{2}$ nanosheets (NS) doped with $\mathrm{Mn}$ (Mn-Ni-S) hydrothermally synthesized over Nickel foam (NF) were studied by Zeng et al.. From theoretical and structural analysis, it was determined that $\mathrm{Mn}$ atoms do not alter the crystalline structure of $\mathrm{Ni}_{2} \mathrm{~S}$ but favor the dissociation of water molecules (Volmer-step), lowering the electronegativity of $\mathrm{Ni}$, leading to a reconfiguration of $\mathrm{Ni}$ electronic structure and the weakening of the Ni-H bond. Mn-Ni-S/nickel foam (NF) outperformed $\mathrm{NiS}_{2} / \mathrm{NF}$ in HER electrocatalysis due to (1) the increase in the number of active sites, by an increase of defects, and accessibility to the electrolyte due to 

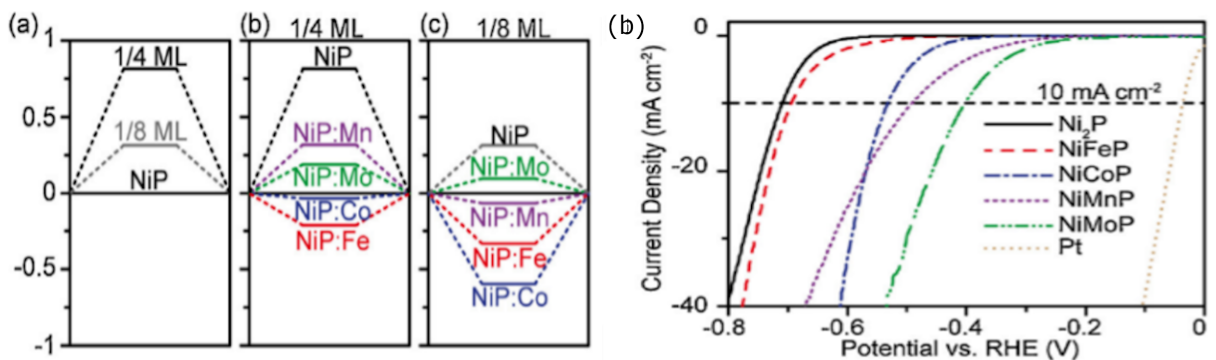

Figure 12. (a) $\Delta G_{H}$ of $\mathrm{NiP}$ with different degree of $\mathrm{H}$ coverage, (b) $\Delta G_{H} \mathrm{NiP}$ and transition metal doped NiP at a $1 / 4 \mathrm{H}$ coverage, (c) $\Delta G_{H} \mathrm{NiP}$ at a $1 / 8 \mathrm{H}$ coverage. (d) LSV for each electrocatalyst evaluated and the $\eta$ required to achieve a current density of $10 \mathrm{~mA} \mathrm{~cm}^{-2}$. Figures retrieved from [168].

the nanosheet structure, (2) the acceleration of mass/charge transport because of the high interconnection between sheets and the void spaces generated in the morphology obtained, and (3) the use of nickel foam as substrate, without the need of binders promoted an intimate contact that produced efficient paths for mass/charge transport. Finally, their activity in an alkaline electrolyte $(1 \mathrm{M} \mathrm{KOH})$, neutral electrolyte (1M PBS, $p \mathrm{H}$ 7), and seawater was tested; for alkaline and neutral water electrolysis, the performance parameters are reported in Table 3. The electrocatalytic activity was higher in alkaline electrolytes, but in both electrolytes, Mn-Ni-S/NF displayed robust long-term durability and stability, up to $24 \mathrm{~h}$ with minimal degradation. In seawater, Mn-Ni-S/NF delivered $10 \mathrm{~mA} \mathrm{~cm}^{-2}$ at an $\eta$ of $301 \mathrm{mV}$. Due to impurities, it was stable for $10 \mathrm{~h}$ and did not present side reactions. The stability and high efficiency were attributed to the absence of binder and the strong interaction between NF and Mn-Ni-S.

Pyrite structures have demonstrated to be efficient electrocatalyst for HER [124], [150] due to their earth abundance, low cost and stability in alkaline [150], acid [163] and neutral [150] electrolyte. Through thermal conversion, Zhuo et al. evaluated the effect of adding Se to $\mathrm{NiP}_{2}\left(\mathrm{NiP}_{1.93} \mathrm{Se}_{0.07}\right)$ and $\mathrm{P}$ to $\mathrm{NiSe}_{2}\left(\mathrm{NiP}_{0.09} \mathrm{Se}_{1.91}\right)$ for acid $(0.5 \mathrm{M}$ $\mathrm{H}_{2} \mathrm{SO}_{4}$ ) HER electrocatalysis [163]. The highest electrocatalytic activity was achieved by $\mathrm{NiP}_{1.93} \mathrm{Se}_{0.07}$ (Table 3). To further enhance the electrocatalytical activity of this material, it was grown on carbon fiber paper. The overpotentials to achieve a current density of $10 \mathrm{~mA} \mathrm{~cm}^{-2}$ and the $m_{T}$ were 84 and $41 \mathrm{mV} \mathrm{dec}^{-1}$.

Finally, heterostructures, as mentioned before, can further enhance the catalytic performance of Ni-based materials for HER. Xu et al. developed $\mathrm{Ni} / \mathrm{NiO} / \mathrm{CoSe}_{2}$ hybrid by solvothermal synthesis and subsequent annealing treatment [169]. This nanocomposite exhibited a smaller $m_{T}$, of $39 \mathrm{mV} \mathrm{dec}^{-1}$, compared to CoSe 2 nanobelts $\left(48 \mathrm{mV} \mathrm{dec}^{-1}\right)$. The faster reaction kinetic for the nanocomposite was due to the synergic effect between metallic $\mathrm{Ni}$, which functioned as a conductive path that reduced the internal resistance, $\mathrm{NiO}$, weakened the $\mathrm{O}-\mathrm{H}$ bond of the molecule of water adsorbed, and $\mathrm{CoSe}_{2}$ nanobelts, a substrate that provided active sites.

\subsection{Nickel-based bifunctional electrocatalysts for overall water electrolysis}

The design of a bifunctional Ni-based electrocatalyst that can efficiently catalyze WE for the industrial production of $\mathrm{H}_{2}$ in acid, neutral and alkaline electrolytes is a challenge. The precise control of composition, morphology, and structure of electrocatalysts can lead to a material capable of efficiently catalyzing HER and OER in the same electrolyte. Kumar and Bhattacharyya [126] synthesized by coprecipitation NiFe-oxide nanocubes (NiFe-NC) and compared their activity for overall alkaline water splitting with $\mathrm{NiFe}$ oxide nanoparticles (NP). NiFe-NC delivered a current density of $10 \mathrm{~mA} \mathrm{~cm}^{-2}$ at $1.67 \mathrm{~V}$, while NiFe-NP required $1.90 \mathrm{~V}$ (Figure 13a). NiFe-NC outperformed NiFe-NP because of (1) the mesoporous structure that facilitates mass transport and the efficient liberation of gas evolved bubbles from the large ECSA, (2) the edges and corners of NC increased 

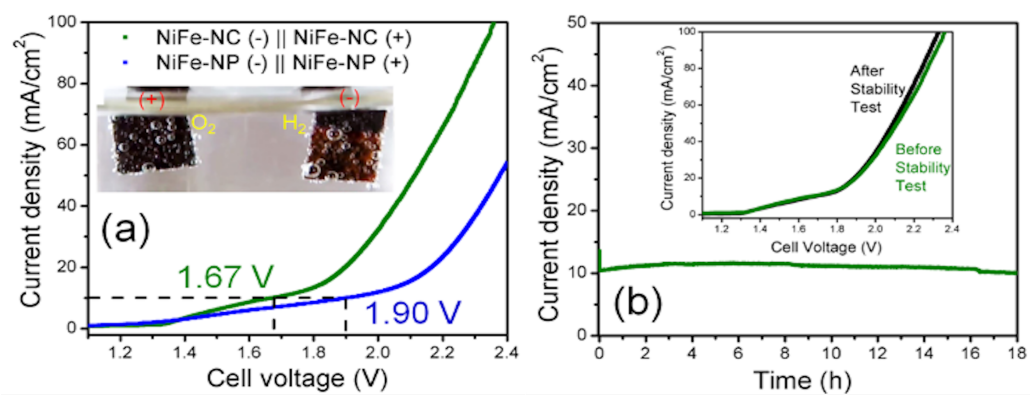

Figure 13. (a) Polarization curves for the overall water electrolysis with NiFe-oxide nanocube (NiFe-NC) as anode and cathode (green) and NiFe-oxide nanoparticles (NiFe-NP) as anode and cathode (blue). (b) Chronoamperometry for overall water electrolysis at $1.7 \mathrm{~V}$ for $\mathrm{NiFe}-\mathrm{NC}$, inset the LSV curves after and before the stability test. Retrieved from [126].

the number of active sites available, and (3) precise tuning of composition to achieve the optimal content of $\mathrm{Fe}(40 \%)$ that produced the adequate composition of $\alpha / \gamma-\mathrm{Fe}_{2} \mathrm{O}_{3}$. Increased the electrode conductivity, provided efficient paths for electron transfer and suppressed the oxidation of $\mathrm{Ni}^{\mathrm{II}}$ to $\mathrm{Ni}^{\mathrm{III}}$. In this work, $\mathrm{Ni}^{\mathrm{II}}$ was considered the active species, and $\mathrm{Fe} \mathrm{III}^{\mathrm{II}}$ the one in charge of facilitating electrode kinetics. NiFe-NC in overall water electrolysis presented minimal degradation after $18 \mathrm{~h}$ (Figure 13b). Kumar and Bhattacharyya confirmed that efficient and stable Ni-based electrocatalyst could be produced by the precise synthesis techniques that allow the control of structure and composition [126].

Other materials studied for the overall water electrolysis are the layered phosphosulfides $\left(\mathrm{MPS}_{3}\right)$. Song et al. evaluated $\mathrm{Ni}_{1-x} \mathrm{Fe}_{x} \mathrm{PS}_{3}$ structures for water splitting in alkaline media [8]. This type of materials, $\mathrm{MPS}_{3}$, are stable structures but have low OER and HER electrocatalytic activity. Thus, to enhance their electrocatalytic activity, doping can modulate the hydrogen or oxygen adsorption energies and enhance the material's conductivity. In this case, Fe doping must be carefully controlled to achieve an optimal mixture of oxidation states between $\mathrm{Ni}$ and Fe sites. The optimal doping composition was $\mathrm{Ni}_{0.9} \mathrm{Fe}_{0.1} \mathrm{PS}_{3}$, it was stable in HER and OER up to $50 \mathrm{~h}$ at $-30 \mathrm{~mA} \mathrm{~cm}{ }^{-2}$ and $30 \mathrm{~mA} \mathrm{~cm}^{-2}$, respectively. They observed that the material did not suffer superficial changes during HER, but in OER electrocatalysis, it functioned as a precursor for $\mathrm{Ni}(\mathrm{Fe}) \mathrm{OOH}$ and $\mathrm{Ni}(\mathrm{Fe})(\mathrm{OH})_{2}$ in alkaline media. Concluding that $\mathrm{Ni}_{0.9} \mathrm{Fe}_{0.1} \mathrm{PS}_{3}$ is the active material for HER, but in OER, it works as a precursor. $\mathrm{Z}$. Wu et al. evaluated the effect of adding $\mathrm{S}$ to $\mathrm{FeP}$ and $\mathrm{P}$ to FeS [170]. They concluded that the metal coordination with $P$ produces the most effective sites and that the electrocatalytic activity is insensitive to the $\mathrm{S}$ substitution. By structural and compositional analysis, they observed that $\mathrm{P}$ atoms tend to remain on the surface and act as a sacrificing agent to partially protect $\mathrm{Fe}$ and $\mathrm{S}$ atoms from oxidation and consequential inactivation for HER. Finally, they stated that the precise control of the surface and inner layers of the material are essential to effectively modulate the electronic interactions and conductivity that then will modify the adsorption energy of intermediates. So, the precise addition of cations and anions into nickel materials can enhance the electrocatalytic activity for overall water splitting.

\section{Future Perspectives}

Extensive theoretical and experimental investigations have been done to elucidate the mechanism of OER, HER, or water electrolysis in Ni-based materials, the role of structure and composition. But, there is still a need for the development of low-cost materials with high electrocatalytic activity, and high stability [63]. The main focus on Ni-based catalysts that can be deduced from the vast information available in the literature are the following $[14,63,66]$ :

1. Elucidation of water electrolysis mechanism in nickel-based electrocatalysts. 
2. Development of synthesis techniques with high control of morphology, structure and composition for nickel-based electrocatalyst.

3. Design of nickel-based electrocatalyst with high stability in acid and neutral media

Hydrothermal, solvothermal, and coprecipitation synthesis techniques have been designed to be an accessible and economical route for Ni-based electrocatalysts. They have been paired up with theoretical studies, DFT [162,166,167], and in-situ experimental techniques, like in-situ Raman spectroscopy [155] or surface interrogation scanning electron microscopy [161] to establish or approximate the mechanism of specific Ni-based electrocatalyst for HER and OER. But, if the goal is the production at an industrial scale of $\mathrm{H}_{2}$ from water electrolysis, accessible, precise, and robust techniques for the synthesis and characterization of Ni-based electrocatalyst must be developed. Galvanostatic deposition and elimination voltammetry (EV) are electrochemical techniques for the synthesis and characterization of materials accessible, fast to implement, and with high control of parameters. Galvanostatic deposition can produce metallic films with electrocatalytic activity [141,148] and is easy to scale for mass production. Martinez compared galvanostatic and potentiostatic deposition of Ni NP in ITO and concluded that the deposits produced galvanostatic deposition yield smaller particle sizes with less dispersion. They obtained a particles size of $137 \pm 43 \mathrm{~nm}$ with applied pulses of $5 \mathrm{~mA}$ for $1000 \mathrm{~ms}$ [140]. Then, Medrano deposited NiPt films on gold and evaluated their electrocatalytic activity towards water electrolysis; these films reached an $\eta$ of 22 $\mathrm{mV}$ at $10 \mathrm{~mA} \mathrm{~cm}^{-2}$. Later, Salinas-Quezada et al. observed a dependency between the applied deposition current applied and the electrocatalytic activity of nickel films. When lower deposition current values were applied, 22-33 $\mu \mathrm{A}$, the electrocatalytic activity favored methanol oxidation, and with higher deposition currents, 38-66 $\mu \mathrm{A}$, OER was favored. This was attributed to changes in the growth regime because, during this stage, the geometric area defines the diffusion field of metallic ions. So, electrocatalysts produced by galvanostatic deposition can favor a specific electrocatalytic process. Another advantage of the use of galvanostatic deposition is the direct deposition on the desired substrate. This eliminates the necessity to use a binder or a conductive agent, which only increases the dead volume, decreases the activity of the material, and, if there is not a good interaction between substrate-binder-electrocatalyst, decreases the stability of the material. The common synthesis technique for industrial application is the chemical synthesis of powders. Some drawbacks of this synthesis technique are the need to transfer the electrocatalyst to a conductive substrate[12], and the low density and efficiency due to the fact that this material reaches its maximum performance at very low geometrical loading [79]. Two of the substrates employed in different types of deposition are carbon materials[163,171] and NF [122]. It has been reported an increase in ECSA and in electrical conductivity due to (1) the intimate contact between substrate and catalyst, (2) the efficient liberation of products from the active sites, and (3) the generation of efficient pathways for mass/charge transport $[150,163,171]$. This strategy not only could increase electrocatalytic activity but also the stability would be enhanced by the facile liberation of gas evolved bubbles from the active surface of the electrode to avoid electrode damaging, and the decrease of ECSA due to bubbles accumulation [79].

To efficiently synthesize Ni-based electrocatalyst is necessary to elucidate the mechanism of action, know the active sites, the role of transition metal and impurities, and the structural transformation that undergoes the material during HER, OER, or water electrolysis. The detailed and precise characterization of composition, morphology, and structure is necessary to develop accessible and economical characterization techniques and eliminate impurities that may alter electrocatalytic activity. Trotochaud et al. developed a protocol for $\mathrm{KOH}$ purification by decantation to address the presence of impurities that may alter the output of the electrocatalyst characterization in alkaline electrolyte [159]. A clear difference in the cyclic voltammograms of purified $\mathrm{KOH}$ and electrolyte with intentional or unintentional added Fe was observed, the redox peak corresponding to $\mathrm{Ni}^{\mathrm{II}} / \mathrm{Ni}^{\mathrm{III}}$ shifted to more positive values with the increase of Fe con- 


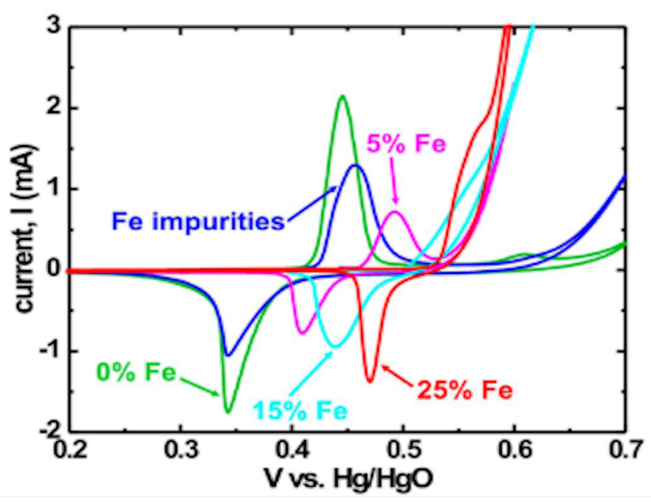

Figure 14. Cyclic voltammograms of $\mathrm{Ni}_{1-x} \mathrm{Fe}_{x}(\mathrm{OH})_{2} / \mathrm{Ni}_{1-x} \mathrm{Fe}_{x} \mathrm{OOH}$ films. Retrieved from [159].

tent (Figure 19). So, to elucidate the correct mechanism, the development of purification protocols for diver impurities and electrolytes is required.

Characterization techniques, like X-ray diffraction (XRD), X-ray photoelectron spectroscopy (XPS), absorption spectroscopy (XAS), scanning electron microscopy (SEM), transmission electron microscopy (TEM), Raman spectroscopy, and Inductively coupled plasma mass spectrometry (ICP-MS), have been used to study the initial and final conditions of the Ni-based electrocatalyst. However, the study of the process in the interface needs to be further investigated with economical techniques. Elimination voltammetry $(\mathrm{EV})$ is an attractive alternative because it enables the detection of minor processes in the electrode by a mathematical treatment of electrochemical signals. As the total current is the sum of individual currents, charging current $\left(I_{c}\right)$, kinetic current $\left(I_{k}\right)$, and diffusion current $\left(I_{d}\right)$. The total current at three different scan rates is combined, and the unwanted currents are eliminated using linear elimination functions. The three currents that result, $I_{c}, I_{k}$, and $I_{d}$, can be studied [172]. An advantage of this technique is that validation can be done by computational modeling of the desired process [173] and its mathematical treatment by EV, which could also serve as a reference point to compare the deviations of the real process from the ideal or theoretical. Oriňáková studied the electrodeposition of nickel in paraffin impregnated graphite electrode (PIGE) using chloride and sulfate electrolytes. The data recollected from cyclic voltammogram at three different scan rates were studied by EV and a theoretical model to validate the results obtained. This technique allowed the identification of two different processes of nickel electrodeposition depending on the electrolyte implemented [174].

\section{Conclusions}

This review has summarized the water electrolysis mechanism and the development of nickel-based electrocatalysts for HER, OER, and overall water electrolysis. Water electrolysis is an ideal alternative for $\mathrm{H}_{2}$ production, but the lack of efficient and cheap electrocatalysts limits its industrial application. It has been established that the mechanism of HER and OER must be elucidated to develop efficient nickel-based materials for water electrolysis. Also, the role of heteroatoms and structural and morphological features must be considered because they may enhance or diminish the electrocatalytic activity. On the other hand, the accurate determination of performance parameters is critical to correctly assessing the electrocatalytic activity of nickel-based electrocatalysts. By considering these aspects, a cost-effective nickel-based electrocatalyst can be designed for OER, HER, or ultimately for the overall water electrolysis. The strategies implemented are modifying composition by doping, modifying structure or morphology by the induction of defects or the increment of electrocatalytic active surface area, and implementing different substrates. However, there is still room for improvement in the synthesis and characterization of these materials. The synthesis of nickel-based electrocatalyst with controlled structure and composition may provide enhanced electrocatalytic activity by 
optimizing the electronic conductivity, binding strength to intermediate species, and the lifetime of the material. Additionally, the development of accessible characterization techniques that allow the study of the electrocatalytic process at the interface of electrocatalyst and electrolyte is needed for the accurate study of OER, HER, or overall water electrolysis on nickel-based electrocatalysts. Finally, from the literature reviewed in this work, it can be concluded that the ideal electrocatalyst is the bifunctional nickel-based electrocatalyst. A nickel-based heterostructure can efficiently catalyze both HER and OER processes, facilitating the industrial scaling of water electrolysis, increment stability, and reducing the material's cost. A clear strategy to achieve this is the implementation of a conductive and porous substrate and the precise doping of nickel materials to produce quaternary structures with tuned electrical conductivity, adsorption energy, and structure that can facilitate the evolution of $\mathrm{H}_{2}$ and $\mathrm{O}_{2}$. However, aspects previously mentioned (mechanism, role of heteroatoms, structural, morphological features, and performance parameters) must be evaluated to optimize the material's activity.

Author Contributions: Conceptualization, M.V. and D.A.C.Y.; data curation, Z.A.O; writingoriginal draft preparation, Z.A.O.; writing—review and editing, O.R., J.L.C.D., L.M.M, D.A.C.Y, M.V; supervision, D.A.C.Y and M.V; All authors have read and agreed to the published version of the manuscript.

Funding: This research received no external funding.

Acknowledgments: The authors express their gratitude to the School of Engineering and Sciences of Tecnologico de Monterrey for the support received for the development of this research through the Research Chair of Photonics and Quantum Systems.

Conflicts of Interest: The authors declare no conflict of interest.

\section{References}

1. Nocera, D.G. Chemistry of Personalized Solar Energy. Inorg. Chem. 2009, 48, 10001-10017.

2. Mazloomi, K.; Gomes, C. Hydrogen as an energy carrier: Prospects and challenges. Renew. Sust. Energ. Rev. 2012, 16, 3024-3033.

3. Rossmeisl, J.; Qu, Z.W.; Zhu, H.; Kroes, G.J.; Nørskov, J. Electrolysis of water on oxide surfaces. J. Electroanal. Chem. 2007, 607, 83-89. Theoretical and Computational Electrochemistry.

4. Zeng, K.; Zhang, D. Recent progress in alkaline water electrolysis for hydrogen production and applications. Prog. Energy Combust. Sci. 2010, 36, 307-326.

5. IEA. The Future of Hydrogen; International Energy Agency, 2019; p. 203.

6. Sequeira, C.A.C.; Santos, D.M.F. Electrochemical Routes for Industrial Synthesis. J. Braz. Chem. Soc. 2009, 20, 387-406.

7. Yates, J.; Daiyan, R.; Patterson, R.; Egan, R.; Amal, R.; Ho-Baille, A.; Chang, N.L. Technoeconomic Analysis of Hydrogen Electrolysis from Off-Grid Stand-Alone Photovoltaics Incorporating Uncertainty Analysis. Cell Reports Physical Science 2020, 1, 100209.

8. Song, B.; Li, K.; Yin, Y.; Wu, T.; Dang, L.; Cabán-Acevedo, M.; Han, J.; Gao, T.; Wang, X.; Zhang, Z.; Schmidt, J.R.; Xu, P.; Jin, S. Tuning Mixed Nickel Iron Phosphosulfide Nanosheet Electrocatalysts for Enhanced Hydrogen and Oxygen Evolution. ACS Catal. 2017, 7, 85498557.

9. Yu, S.; Wang, Y.; Li, X.; Yu, F.; Li, W. The factors affecting the reproducibility of micro-volume DNA mass quantification in Nanodrop 2000 spectrophotometer. Optik 2017, 145, 555-560.

10. Gao, M.; Sheng, W.; Zhuang, Z.; Fang, Q.; Gu, S.; Jiang, J.; Yan, Y. Efficient Water Oxidation Using Nanostructured $\alpha$-Nickel-Hydroxide as an Electrocatalyst. Journal of the American Chemical Society 2014, 136, 7077-7084.

11. Santos, D.M.F.; Sequeira, C.A.C.; Figueiredo, J.L. Hydrogen production by alkaline water electrolysis. Quim. Nova 2013, 36, 1176-1193.

12. Gong, M.; Wang, D.Y.; Chen, C.C.; Hwang, B.J.; Da, H. A mini review on nickel-based electrocatalysts for alkaline hydrogen evolution reaction. Nano Res. 2016, 9, 28-46.

13. Fang, M.; Dong, G.; Wei, R.; Ho, J.C. Hierarchical Nanostructures: Design for Sustainable Water Splitting. Adv. Energy Mater. 2017, 7, 1700559.

14. Wu, Z.P.; Lu, X.F.; Zang, S.Q.; Lou, X.W.D. Non-Noble-Metal-Based Electrocatalysts toward the Oxygen Evolution Reaction. Adv. Funct. Mater. 2020, 30, 1910274. 
15. Suen, N.T.; Hung, S.F.; Quan, Q.; Zhang, N.; Xu, Y.J.; Chen, H.M. Electrocatalysis for the oxygen evolution reaction: recent development and future perspectives. Chem. Soc. Rev. 2017, 46, 337-365.

16. Hoang, T.T.H.; Gewirth, A.A. High Activity Oxygen Evolution Reaction Catalysts from Additive-Controlled Electrodeposited Ni and NiFe Films. ACS Catal. 2016, 6, 1159-1164.

17. Sun, X.; Xu, K.; Fleischer, C.; Liu, X.; Grandcolas, M.; Strandbakke, R.; Bjørheim, T.S.; Norby, T.; Chatzitakis, A. Earth-Abundant Electrocatalysts in Proton Exchange Membrane Electrolyzers. Catalysts 2018, 8 .

18. Mahmood, N.; Yao, Y.; Zhang, J.W.; Pan, L.; Zhang, X.; Zou, J.J. Electrocatalysts for Hydrogen Evolution in Alkaline Electrolytes: Mechanisms, Challenges, and Prospective Solutions. Adv. Sci. 2018, 5, 1700464.

19. Savadogo, O. Water electrolysis in acid medium. Hem. Ind. 2000, 54, 95-101.

20. Schalenbach, M.; Tjarks, G.; Carmo, M.; Lueke, W.; Mueller, M.; Stolten, D. Acidic or Alkaline? Towards a New Perspective on the Efficiency of Water Electrolysis. J. Electrochem. Soc. 2016, 163, F3197-F3208.

21. Jamesh, M.I.; Sun, X. Recent progress on earth abundant electrocatalysts for oxygen evolution reaction (OER) in alkaline medium to achieve efficient water splitting - A review. J. Power Sources 2018, 400, 31-68.

22. Zheng, X.; Song, X.; Wang, X.; Zhang, Z.; Sun, Z.; Guo, Y. Nickel-copper bimetal organic framework nanosheets as a highly efficient catalyst for oxygen evolution reaction in alkaline media. New J. Chem. 2018, 42, 8346-8350.

23. McCrory, C.C.L.; Jung, S.; Ferrer, I.M.; Chatman, S.M.; Peters, J.C.; Jaramillo, T.F. Benchmarking Hydrogen Evolving Reaction and Oxygen Evolving Reaction Electrocatalysts for Solar Water Splitting Devices. J. Am. Chem. Soc. 2015, 137, 4347-4357.

24. Xiao, P.; Chen, W.; Wang, X. A Review of Phosphide-Based Materials for Electrocatalytic Hydrogen Evolution. Adv. Energy Mater. 2015, 5, 1500985.

25. Peng, J.; Dong, W.; Wang, Z.; Meng, Y.; Liu, W.; Song, P.; Liu, Z. Recent advances in 2D transition metal compounds for electrocatalytic full water splitting in neutral media. Mater. Today Adv. 2020, 8, 100081 .

26. Li, W.; Jiang, N.; Hu, B.; Liu, X.; Song, F.; Han, G.; Jordan, T.J.; Hanson, T.B.; Liu, T.L.; Sun, Y. Electrolyzer Design for Flexible Decoupled Water Splitting and Organic Upgrading with Electron Reservoirs. Chem 2018, 4, 637-649.

27. Nørskov, J.K.; Studt, F.; Abild-Pedersen, F.; Bligaard, T., Surface Electrocatalysis. In Fundamental Concepts in Heterogeneous Catalysis; John Wiley \& Sons, Ltd, 2014; chapter 11, pp. 155-174.

28. Xu, Y.; Chen, Y.; Wu, J.; Li, D.; Ju, H.; Zheng, J. The determination of the kinetic parameters of electrochemical reaction in chemical power sources: A critical review. Int. J. Hydrog. Energy 2010, 35, 6366-6380.

29. Li, D.; Shi, J.; Li, C. Transition-Metal-Based Electrocatalysts as Cocatalysts for Photoelectrochemical Water Splitting: A Mini Review. Small 2018, 14, 1704179.

30. Appel, A.M.; Helm, M.L. Determining the Overpotential for a Molecular Electrocatalyst. ACS Catal. 2014, 4, 630-633.

31. Butler-Volmer equation.

32. Elgrishi, N.; Rountree, K.J.; McCarthy, B.D.; Rountree, E.S.; Eisenhart, T.T.; Dempsey, J.L. A Practical Beginner's Guide to Cyclic Voltammetry. J. Chem. Educ. 2018, 95, 197-206.

33. Krischer, K.; Savinova, E.R., Fundamentals of Electrocatalysis. In Handbook of Heterogeneous Catalysis; Wiley-VCH Verlag GmbH \& Co. KGaA, 2008; chapter 8, pp. 1873-1905.

34. Thompson, R.Q.; Craig, N.C. Unified Electroanalytical Chemistry: Application of the Concept of Electrochemical Equilibrium. J. Chem. Educ. 2001, 78, 928.

35. Shinagawa, T.; Garcia-Esparza, A.; Takanabe, K. nsight on Tafel slopes from a microkinetic analysis of aqueous electrocatalysis for energy conversion. J. Am. Chem. Soc. 2015, 5, 13801.

36. Barbir, F. Chapter Three - Fuel Cell Electrochemistry. In PEM Fuel Cells (Second Edition), Second Edition ed.; Barbir, F., Ed.; Academic Press: Boston, 2013; pp. 33-72.

37. Smith, R.M.; Flanagan, R.J.; Perrett, D.; Whelpton, R. Basic electrochemistry for the separation scientist. In Electrochemical Detection in HPLC: Analysis of Drugs and Poisons; The Royal Society of Chemistry, 2005; pp. 6-20.

38. Higson, S. Analytical Chemistry; Oxford University Press, 2004; pp. 567-590.

39. Frank, Y.; Wan, K., Characterization of Nanofibers. In Introduction to Nanofiber Materials; Cambridge University Press, 2014; chapter 6. 
40. Medrano, A. Electrodeposición de nanoestructuras de platino-níquel con actividad electrocatalítica para su aplicación en la electrólisis del agua. PhD thesis, Tecnologico de Monterrey, Monterrey, NL, 2019.

41. Yu, X.; Zhao, J.; Zheng, L.R.; Tong, Y.; Zhang, M.; Xu, G.; Li, C.; Ma, J.; Shi, G. Hydrogen Evolution Reaction in Alkaline Media: Alpha- or Beta-Nickel Hydroxide on the Surface of Platinum? ACS Energy Lett. 2018, 3, 237-244.

42. Walsh, P., Principles of Catalysis. In Organotransition Metal Chemistry: From Bonding to Catalysis; University Science Books, 2010; chapter 14, p. 545.

43. Onsan, Z.I., Microkinetic analysis of heterogeneous catalytic systems. In Multiphase Catalytic Reactors; John Wiley \& Sons, Ltd, 2016; chapter 2, pp. 17-52.

44. Quezada, M.P.S. Estudio de la electrodeposición de nanopartículas de níquel para la obtención de superficies con actividad electrocatalítica. PhD thesis, Tecnologico de Monterrey, Monterrey, NL, 2018.

45. Dupont, M.; Hollenkamp, A.F.; Donne, S.W. Electrochemically active surface area effects on the performance of manganese dioxide for electrochemical capacitor applications. Electrochim. Acta 2013, 104, 140-147.

46. Lukaszewski, M.; Soszko, M.; Czerwiński, A. Electrochemical methods of real surface area determination of noble metal electrodes - an overview. Int. J. Electrochem. Sci. 2016, 11, 4442-4469. doi:10.20964/2016.06.71.

47. Bueno, P.R., Electrochemical capacitive biosensors for point-of-care diagnostics: principles and applications. In Nanobiosensors for Personalized and Onsite Biomedical Diagnosis; Healthcare Technologies, Institution of Engineering and Technology, 2016; pp. 293-316.

48. Morales-Guio, C.G.; Liardet, L.; Hu, X. Oxidatively Electrodeposited Thin-Film Transition Metal (Oxy)hydroxides as Oxygen Evolution Catalysts. J. Am. Chem. Soc. 2016, 138, 89468957.

49. Swierk, J.R.; Klaus, S.; Trotochaud, L.; Bell, A.T.; Tilley, T.D. Electrochemical Study of the Energetics of the Oxygen Evolution Reaction at Nickel Iron (Oxy)Hydroxide Catalysts. J. Phys. Chem. C 2015, 119, 19022-19029.

50. Lyons, M.E.; Brandon, M.P. The significance of electrochemical impedance spectra recorded during active oxygen evolution for oxide covered $\mathrm{Ni}$, Co and Fe electrodes in alkaline solution. J. Electroanal. Chem. 2009, 631, 62-70.

51. Doyle, R.L.; Godwin, I.J.; Brandon, M.P.; Lyons, M.E.G. Redox and electrochemical water splitting catalytic properties of hydrated metal oxide modified electrodes. Phys. Chem. Chem. Phys. 2013, 15, 13737-13783.

52. Batchellor, A.S.; Boettcher, S.W. Pulse-Electrodeposited Ni-Fe (Oxy)hydroxide Oxygen Evolution Electrocatalysts with High Geometric and Intrinsic Activities at Large Mass Loadings. ACS Catal. 2015, 5, 6680-6689.

53. Hart, D. Hydrogen. In Dictionary of Energy, Second Edition ed.; Cleveland, C.J.; Morris, C., Eds.; Elsevier: Boston, 2015; pp. 297-307.

54. Chang, B.Y.; Park, S.M. Electrochemical Impedance Spectroscopy. Annu. Rev. Anal. Chem. 2010, 3, 207-229.

55. Doyle, R.L.; Lyons, M.E.G. An electrochemical impedance study of the oxygen evolution reaction at hydrous iron oxide in base. Phys. Chem. Chem. Phys. 2013, 15, 5224-5237.

56. McCrory, C.C.L.; Jung, S.; Peters, J.C.; Jaramillo, T.F. Benchmarking Heterogeneous Electrocatalysts for the Oxygen Evolution Reaction. Journal of the American Chemical Society 2013, 135, 16977-16987, [https://doi.org/10.1021/ja407115p]. PMID: 24171402, doi: $10.1021 /$ ja407115p.

57. Arvia, A.J.; Bolzán, A.E.; Pasquale, M.A., Electrocatalysis: A Survey of Fundamental Concepts. In Catalysis in Electrochemistry; John Wiley \& Sons, Ltd, 2011; chapter 2, pp. 17-65.

58. Valtiner, M.; Banquy, X.; Kristiansen, K.; Greene, G.W.; Israelachvili, J.N. The Electrochemical Surface Forces Apparatus: The Effect of Surface Roughness, Electrostatic Surface Potentials, and Anodic Oxide Growth on Interaction Forces, and Friction between Dissimilar Surfaces in Aqueous Solutions. Langmuir 2012, 28, 13080-13093.

59. Yu, F.; Zhou, H.; Huang, Y.; Sun, J.; Qin, F.; Bao, J.; III, W.A.G.; Chen, S.; Ren, Z. Highperformance bifunctional porous non-noble metal phosphide catalyst for overall water splitting. Nat. Commun. 2018, 9.

60. Sharp, I.D.; Atwater, H.A.; Lewerenz, H.J., Eds. Integrated Solar Fuel Generators; Energy and Environment Series, The Royal Society of Chemistry, 2019; pp. P001-544. 
61. Cheng, N.; Liu, Q.; Tian, J.; Sun, X.; He, Y.; Zhai, S.; Asiri, A.M. Nickel oxide nanosheets array grown on carbon cloth as a high-performance three-dimensional oxygen evolution electrode. Int. J. Hydrog. Energy 2015, 40, 9866-9871.

62. Lee, Y.; Suntivich, J.; May, K.J.; Perry, E.E.; Shao-Horn, Y. Synthesis and Activities of Rutile $\mathrm{IrO} 2$ and $\mathrm{RuO} 2$ Nanoparticles for Oxygen Evolution in Acid and Alkaline Solutions. J. Phys. Chem. Lett. 2012, 3, 399-404.

63. Han, L.; Dong, S.; Wang, E. Transition-Metal (Co, Ni, and Fe)-Based Electrocatalysts for the Water Oxidation Reaction. Adv. Mater. 2016, 28, 9266-9291.

64. Kötz, R.; Lewerenz, H.J.; Stucki, S. XPS Studies of Oxygen Evolution on Ru and $\mathrm{RuO}_{2}$ Anodes. J. Electrochem. Soc. 1983, 130, 825-829.

65. Nørskov, J.K.; Bligaard, T.; Logadottir, A.; Kitchin, J.R.; Chen, J.G.; Pandelov, S.; Stimming, U. Trends in the Exchange Current for Hydrogen Evolution. J. Electrochem. Soc. 2005, 152, J23.

66. Vij, V.; Sultan, S.; Harzandi, A.M.; Meena, A.; Tiwari, J.N.; Lee, W.G.; Yoon, T.; Kim, K.S. Nickel-Based Electrocatalysts for Energy-Related Applications: Oxygen Reduction, Oxygen Evolution, and Hydrogen Evolution Reactions. ACS Catal. 2017, 7, 7196-7225.

67. Wang, Z.; Liu, M.; Du, J.; Lin, Y.; Wei, S.; Lu, X.; Zhang, J. A facile co-precipitation synthesis of robust FeCo phosphate electrocatalysts for efficient oxygen evolution. Electrochim. Acta 2018, 264, 244-250.

68. Quaino, P.; Juarez, F.; Santos, E.; .; Schmickler, W. High-performance bifunctional porous non-noble metal phosphide catalyst for overall water splitting. Beilstein J. Nanotechnol. 2014, $5,846-854$.

69. Nørskov, J.K.; Rossmeisl, J.; Logadottir, A.; Lindqvist, L.; Kitchin, J.R.; Bligaard, T.; Jónsson, $\mathrm{H}$. Origin of the Overpotential for Oxygen Reduction at a Fuel-Cell Cathode. The Journal of Physical Chemistry B 2004, 108, 17886-17892.

70. Bagger, A.; Castelli, I.E.; Hansen, M.H.; Rossmeisl, J., Fundamental Atomic Insight in Electrocatalysis. In Handbook of Materials Modeling: Applications: Current and Emerging Materials; Andreoni, W.; Yip, S., Eds.; Springer International Publishing: Cham, 2020; pp. 1473-1503.

71. Greeley, J. Theoretical Heterogeneous Catalysis: Scaling Relationships and Computational Catalyst Design. Annual Review of Chemical and Biomolecular Engineering 2016, 7, 605-635.

72. Song, F.; Busch, M.M.; Lassalle-Kaiser, B.; Hsu, C.S.; Petkucheva, E.; Bensimon, M.; Chen, H.M.; Corminboeuf, C.; Hu, X. An Unconventional Iron Nickel Catalyst for the Oxygen Evolution Reaction. ACS Central Science 2019, 5, 558-568.

73. Lu, Z.; Wang, H.; Kong, D.; Yan, K.; Hsu, P.C.; Zheng, G.; Yao, H.; Liang, Z.; Sun, X.; Cu, Y. Electrochemical tuning of layered lithium transition metal oxides for improvement of oxygen evolution reaction. Nat. Commun. 2014, 5.

74. Zhou, W.; Sunarso, J. Enhancing Bi-functional Electrocatalytic Activity of Perovskite by Temperature Shock: A Case Study of LaNiO3- $\delta$. J. Phys. Chem. Lett. 2013, 4, 2982-988.

75. Song, F.; Hu, X. Exfoliation of layered double hydroxides for enhanced oxygen evolution catalysis. Nat. Commun. 2014, 5, 4477.

76. Zeng, L.; Yang, L.; Lu, J.; Jia, J.; Yu, J.; Deng, Y.; Shao, M.; Zhou, W. One-step synthesis of Fe-Ni hydroxide nanosheets derived from bimetallic foam for efficient electrocatalytic oxygen evolution and overall water splitting. Chin. Chem. Lett. 2018, 29, 1875-1878.

77. Jia, Y.; Zhang, L.; Gao, G.; Chen, H.; Wang, B.; Zhou, J.; Soo, M.T.; Hong, M.; Yan, X.; Qian, G.; Zou, J.; Du, A.; Yao, X. A Heterostructure Coupling of Exfoliated Ni-Fe Hydroxide Nanosheet and Defective Graphene as a Bifunctional Electrocatalyst for Overall Water Splitting. Adv. Mater. 2017, 29, 1700017.

78. Subbaraman, R.; Tripkovic, D.; Chang, K.C.; Strmcnik, D.; Paulikas, A.P.; Hirunsit, P.; Chan, M.; Greeley, J.; Stamenkovic, V.; Markovic, N.M. Trends in activity for the water electrolyser reactions on $3 \mathrm{~d} \mathrm{M}(\mathrm{Ni}, \mathrm{Co}, \mathrm{Fe}, \mathrm{Mn})$ hydr(oxy)oxide catalysts. Nat. Mater. 2012, 11, 550-557. doi: $10.1038 /$ nmat3313.

79. Xia, C.; Jiang, Q.; Zhao, C.; Hedhili, M.N.; Alshareef, H.N. Selenide-Based Electrocatalysts and Scaffolds for Water Oxidation Applications. Adv. Mater. 2016, 28, 77-85.

80. Jiang, J.; Lu, S.; Gao, H.; Zhang, X.; Yu, H.Q. Ternary FeNiS 2 ultrathin nanosheets as an electrocatalyst for both oxygen evolution and reduction reactions. Nano Energy 2016, 27, 526-534.

81. Stern, L.A.; Feng, L.; Song, F.; Hu, X. Ni2P as a Janus catalyst for water splitting: the oxygen evolution activity of Ni2P nanoparticles. Energy Environ. Sci. 2015, 8, 2347-2351. 
82. Fu, S.; Zhu, C.; Song, J.; Engelhard, M.H.; Li, X.; Du, D.; Lin, Y. Highly Ordered Mesoporous Bimetallic Phosphides as Efficient Oxygen Evolution Electrocatalysts. ACS Energy Lett. 2016, 1, 792-796.

83. Li, Z.; Qiu, G.; Shen, Y.; Wang, X.; Zhuang, W.; Li, J.; Song, M.; Wang, P.; Tian, L. Ultrafine trimetallic oxyphosphide nanoparticles for efficient electrochemical overall water splitting. $J$. Alloys Compd. 2020, 820, 153161.

84. Saad, A.; Shen, H.; Cheng, Z.; Arbi, R.; Guo, B.; Hui, L.S.; Liang, K.; Liu, S.; Attfield, J.P.; Turak, A.; Wang, J.; Yang, M. Mesoporous Ternary Nitrides of Earth-Abundant Metals as Oxygen Evolution Electrocatalyst. J. Phys. Chem. Lett. 2020, 12, 79.

85. Huang, H.; Jung, H.; Jun, H.; Woo, D.Y.; Han, J.W.; Lee, J. Design of grain boundary enriched bimetallic borides for enhanced hydrogen evolution reaction. Chem. Eng. J. 2021, 405, 126977.

86. Kong, F.; Sun, L.; Huo, L.; Zhao, H. In-situ electrochemical self-tuning of amorphous nickel molybdenum phosphate to crystal Ni-rich compound for enhanced overall water splitting. J. Power Sources 2019, 430, 218-227.

87. Dincă, M.; Surendranath, Y.; Nocera, D.G. Nickel-borate oxygen-evolving catalyst that functions under benign conditions. PNAS 2010, 107, 10337-10341.

88. Trasatti, S. Work function, electronegativity, and electrochemical behaviour of metals: III. Electrolytic hydrogen evolution in acid solutions. J. Electroanal. Chem. Interf. Electrochem. 1972, 39, 163-184.

89. Mohamed, R.; Cheng, X.; Fabbri, E.; Levecque, P.; Kötz, R.; Conrad, O.; Schmidt, T.J. Electrocatalysis of Perovskites: The Influence of Carbon on the Oxygen Evolution Activity. J. Electrochem. Soc. 2015, 162, F579-F586.

90. Lopez, K.; Park, G.; Sun, H.J.; An, J.C.; Eom, S.; Shim, J. Electrochemical characterizations of $\mathrm{LaMO}_{3}\left(\mathrm{M}=\mathrm{Co}, \mathrm{Mn}, \mathrm{Fe}\right.$, and Ni) and partially substituted $\mathrm{LaNi}_{x} \mathrm{M}_{1-\mathrm{x}} \mathrm{O}_{3}(\mathrm{x}=0.25$ or 0.5$)$ for oxygen reduction and evolution in alkaline solution. J. Appl. Electrochem. 2015, 45, 313-323.

91. Wang, H.; Wang, J.; Pi, Y.; Shao, Q.; Tan, Y.; Huang, X. Double Perovskite LaFe ${ }_{x} \mathrm{Ni}_{1-\mathrm{x}} \mathrm{O}_{3}$ Nanorods Enable Efficient Oxygen Evolution Electrocatalysis. Angew. Chem. Int. Ed. 2019, 58, 2316-2320.

92. Payne, J.L.; Percival, J.D.; Giagloglou, K.; Crouch, C.J.; Carins, G.M.; Smith, R.I.; Comrie, R.; Gover, R.K.B.; Irvine, J.T.S. In-Situ Thermal Battery Discharge using NiS2 as a Cathode Material. ChemElectroChem 2017, 4, 1916-1923.

93. Anantharaj, S.; Noda, S. Amorphous Catalysts and Electrochemical Water Splitting: An Untold Story of Harmony. Small 2020, 16, 1905779.

94. Nikolov, I.; Darkaoui, R.; Zhecheva, E.; Stoyanova, R.; Dimitrov, N.; Vitanov, T. Electrocatalytic activity of spinel related cobalties $\mathrm{M}_{\mathrm{x}} \mathrm{CO}_{3-\mathrm{x}} \mathrm{O}_{4}(\mathrm{M}=\mathrm{Li}, \mathrm{Ni}, \mathrm{Cu})$ in the oxygen evolution reaction. J. Electroanal. Chem. 1997, 429, 157-168.

95. Li, M.; Xiong, Y.; Liu, X.; Bo, X.; Zhang, Y.; Han, C.; Guo, L. Facile synthesis of electrospun $\mathrm{MFe}_{2} \mathrm{O}_{4}(\mathrm{M}=\mathrm{Co}, \mathrm{Ni}, \mathrm{Cu}, \mathrm{Mn})$ spinel nanofibers with excellent electrocatalytic properties for oxygen evolution and hydrogen peroxide reduction. Nanoscale 2015, 7, 8920-8930.

96. Ma, T.Y.; Dai, S.; Jaroniec, M.; Qiao, S.Z. Synthesis of Highly Active and Stable Spinel-Type Oxygen Evolution Electrocatalysts by a Rapid Inorganic Self-Templating Method. Chem. Eur. J. 2014, 20, 12669-12676.

97. Martínez-Lázaro, A.; Rico-Zavala, A.; Espinosa-Lagunes, F.; Torres-González, J.; L.ÁlvarezContreras.; Gurrola, M.; Arriaga, L.; Ledesma-García, J.; Ortiz-Ortega, E. Microfluidic water splitting cell using 3D NiFe2O4 hollow spheres. J. Power Sources 2019, 412, 505-513.

98. Chien, H.C.; Cheng, W.Y.; Wang, Y.H.; Wei, T.Y.; Lu, S.Y. Ultralow overpotentials for oxygen evolution reactions achieved by nickel cobaltite aerogels. J. Mater. Chem. 2011, 21, 18180 18182.

99. He, G.; Zhang, W.; Deng, Y.; Zhong, C.; Hu, W.; Han, X. Engineering Pyrite-Type Bimetallic Ni-Doped CoS2 Nanoneedle Arrays over a Wide Compositional Range for Enhanced Oxygen and Hydrogen Electrocatalysis with Flexible Property. Catalysts 2017, 7, 366.

100. Chi, J.Q.; Shang, X.; Liang, F.; Dong, B.; Li, X.; Liu, Y.R.; Yan, K.L.; Gao, W.K.; Chai, Y.M.; Liu, C.G. Facile synthesis of pyrite-type binary nickel iron diselenides as efficient electrocatalyst for oxygen evolution reaction. Appl. Surf. Sci 2017, 401, 17-24.

101. Li, Y.; Hasin, P.; Wu, Y. $\mathrm{Ni}_{\mathrm{x}} \mathrm{Co}_{3-\mathrm{x}} \mathrm{O}_{4}$ Nanowire Arrays for Electrocatalytic Oxygen Evolution. Adv. Mater. 2010, 22, 1926-1929.

102. Zhao, J.; Cai, L.; Li, H.; Shi, X.; Zheng, X. Stabilizing Silicon Photocathodes by SolutionDeposited Ni-Fe Layered Double Hydroxide for Efficient Hydrogen Evolution in Alkaline Media. ACS Energy Lett. 2017, 2, 1939-1946. 
103. Liang, H.; Meng, F.; Cabán-Acevedo, M.; Li, L.; Forticaux, A.; Xiu, L.; Wang, Z.; Jin, S. Hydrothermal Continuous Flow Synthesis and Exfoliation of NiCo Layered Double Hydroxide Nanosheets for Enhanced Oxygen Evolution Catalysis. Nano Lett. 2015, 15, 1421-1427.

104. Wu, T.; Zhang, S.; Bu, K.; Zhao, W.; Bi, Q.; Lin, T.; Huang, J.; Li, Y.; Huang, F. Nickel nitride-black phosphorus heterostructure nanosheets for boosting the electrocatalytic activity towards the oxygen evolution reaction. J. Mater. Chem. A 2019, 7, 22063-22069.

105. Zheng, X.; Zhang, Y.; Liu, H.; Fu, D.; Chen, J.; Wang, J.; Zhong, C.; Deng, Y.; Han, X.; Hu, W. In Situ Fabrication of Heterostructure on Nickel Foam with Tuned Composition for Enhancing Water-Splitting Performance. Small 2018, 14, 1803666.

106. Schaschke, C. amount of substance, 2014.

107. Zhang, C.; Fagan, R.D.; Smith, R.D.L.; Moore, S.A.; Berlinguette, C.P.; Trudel, S. Mapping the performance of amorphous ternary metal oxide water oxidation catalysts containing aluminium. J. Mater. Chem. A 2015, 3, 756-761.

108. He, C.; Wu, X.; He, Z. Amorphous Nickel-Based Thin Film As a Janus Electrocatalyst for Water Splitting. J. Phys. Chem. C 2014, 118, 4578-4584.

109. Smith, R.D.L.; Prévot, M.S.; Fagan, R.D.; Zhang, Z.; Sedach, P.A.; Siu, M.K.J.; Trudel, S.; Berlinguette, C.P. Photochemical Route for Accessing Amorphous Metal Oxide Materials for Water Oxidation Catalysis. Science 2013, 340, 60-63.

110. Schoen, M.A.W.; Calderon, O.; Randell, N.M.; Jimenez-Villegas, S.; Daly, K.M.; Chernikov, R.; Trudel, S. Local structural changes in polyamorphous (Ni,Fe)Ox electrocatalysts suggest a dual-site oxygen evolution reaction mechanism. J. Mater. Chem. A 2021, 9, 13252-13262.

111. Wang, J.; Qiu, T.; Chen, X.; Lu, Y.; Yang, W. Hierarchical hollow urchin-like $\mathrm{NiCo}_{2} \mathrm{O}_{4}$ nanomaterial as electrocatalyst for oxygen evolution reaction in alkaline medium. J. Power Sources 2014, 268, 341-348.

112. Chen, S.; Duan, J.; Ran, J.; Jaroniec, M.; Qiao, S.Z. N-doped graphene film-confined nickel nanoparticles as a highly efficient three-dimensional oxygen evolution electrocatalyst. Energy Environ. Sci. 2013, 6, 3693-3699.

113. Chaudhari, N.K.; Jin, H.; Kim, B.; Lee, K. Nanostructured materials on 3D nickel foam as electrocatalysts for water splitting. Nanoscale 2017, 9, 12231-12247.

114. Yin, H.; Jiang, L.; Liu, P.; Al-Mamun, M.; Wang, Y.; Zhong, Y.L.; Yang, H.; Wang, D.; Tang, Z.; Zhao, H. Remarkably enhanced water splitting activity of nickel foam due to simple immersion in a ferric nitrate solution. Nano Res. 2018, 11, 3959-3971.

115. Cheng, Y.; Shen, P.K.; Jiang, S.P. $\mathrm{NiO}_{\mathrm{x}}$ nanoparticles supported on polyethylenimine functionalized CNTs as efficient electrocatalysts for supercapacitor and oxygen evolution reaction. Int. J. Hydrog. Energy 2014, 39, 20662-20670.

116. Pu, Z.; Liu, Q.; Asiri, A.M.; Sun, X. Ni nanoparticles-graphene hybrid film: one-step electrodeposition preparation and application as highly efficient oxygen evolution reaction electrocatalyst. J Appl Electrochem 2014, 44, 1165-1170.

117. Yan, D.; Li, Y.; Huo, J.; Chen, R.; Dai, L.; Wang, S. Defect Chemistry of Nonprecious-Metal Electrocatalysts for Oxygen Reactions. Adv. Mater. 2017, 29, 1606459.

118. Tang, C.; Zhang, Q. Nanocarbon for Oxygen Reduction Electrocatalysis: Dopants, Edges, and Defects. Adv. Mater. 2017, 29, 1604103.

119. Cai, Z.; Bi, Y.; Hu, E.; Liu, W.; Dwarica, N.; Tian, Y.; Li, X.; Kuang, Y.; Li, Y.; Yang, X.Q.; Wang, H.; Sun, X. Single-Crystalline Ultrathin Co3O4 Nanosheets with Massive Vacancy Defects for Enhanced Electrocatalysis. Adv. Energy Mater. 2018, 8, 1701694.

120. Tung, C.W.; Hsu, Y.Y.; Shen, Y.P.; Zheng, Y.; Chan, T.S.; Sheu, H.S.; Cheng, Y.C.; Chen, H.M. Reversible adapting layer produces robust single-crystal electrocatalyst for oxygen evolution. Nat. Commun. 2015, 6.

121. Gorse, C.; Johnston, D.; Pritchard, M. doping, 2013.

122. Zhang, P.; Li, L.; Nordlund, D.; Chen, H.; Fan, L.; Zhang, B.; Sheng, X.; Daniel, Q.; Sun, L. Dendritic core-shell nickel-iron-copper metal/metal oxide electrode for efficient electrocatalytic water oxidation. Nat. Commun. 2018, 9.

123. Shi, Q.; Fu, S.; Zhu, C.; Song, J.; Du, D.; Lin, Y. Metal-organic frameworks-based catalysts for electrochemical oxygen evolution. Mater. Horiz. 2019, 6, 684-702.

124. Wang, Z.; Li, J.; Tian, X.; Wang, X.; Yu, Y.; Owusu, K.A.; He, L.; Mai, L. Porous Nickel-Iron Selenide Nanosheets as Highly Efficient Electrocatalysts for Oxygen Evolution Reaction. ACS Appl. Mater. Interfaces 2016, 8, 19386-19392. 
125. Cao, Y.; Su, Q.; Che, R.; Du, G.; Xu, B. One-step chemical vapor synthesis of Ni/graphene nanocomposites with excellent electromagnetic and electrocatalytic properties. Synth. Met. 2012, 162, 968-973.

126. Kumar, A.; Bhattacharyya, S. Porous NiFe-Oxide Nanocubes as Bifunctional Electrocatalysts for Efficient Water-Splitting. ACS Appl. Mater. Interfaces 2017, 9, 41906-41915.

127. Lu, X.; Zhao, C. Electrodeposition of hierarchically structured three-dimensional nickel-iron electrodes for efficient oxygen evolution at high current densities. Nat. Commun. 2015, 6.

128. Wu, Y.; He, H. Direct-current electrodeposition of Ni-S-Fe alloy for hydrogen evolution reaction in alkaline solution. Int. J. Hydrog. Energy 2018, 43, 1989-1997.

129. Broicher, C.; Zeng, F.; Artz, J.; Hartmann, H.; Besmehn, A.; Palkovits, S.; Palkovits, R. Facile Synthesis of Mesoporous Nickel Cobalt Oxide for OER - Insight into Intrinsic Electrocatalytic Activity. ChemCatChem 2019, 11, 412-416.

130. Liu, X.; Wang, X.; Yuan, X.; Dong, W.; Huang, F. Rational composition and structural design of in situ grown nickel-based electrocatalysts for efficient water electrolysis. J. Mater. Chem. A 2016, 4, 167-172.

131. Li, Y.; Zhang, H.; Jiang, M.; Kuang, Y.; Sun, X.; Duan, X. Ternary NiCoP nanosheet arrays: An excellent bifunctional catalyst for alkaline overall water splitting. Nano Res. 2016, 9, 2251-2259.

132. Xu, Q.T.; Li, J.C.; Xue, H.G.; Guo, S.P. Binary iron sulfides as anode materials for rechargeable batteries: Crystal structures, syntheses, and electrochemical performance. Journal of Power Sources 2018, 379, 41-52.

133. Yang, G.; Park, S.J. Conventional and Microwave Hydrothermal Synthesis and Application of Functional Materials: A Review. Materials 2019, 12.

134. Xiang, D.; Zhang, B.; Zhang, H.; Shen, L. One-Step Synthesis of Bifunctional Nickel Phosphide Nanowires as Electrocatalysts for Hydrogen and Oxygen Evolution Reactions. Frontiers in Chemistry 2021, 9, 848.

135. Cruz, I.F.; Freire, C.; Araújo, J.P.; Pereira, C.; Pereira, A.M. Chapter 3 - Multifunctional Ferrite Nanoparticles: From Current Trends Toward the Future. In Magnetic Nanostructured Materials; El-Gendy, A.A.; Barandiarán, J.M.; Hadimani, R.L., Eds.; Micro and Nano Technologies, Elsevier, 2018; pp. 59-116.

136. Nawaz, M.; Sliman, Y.; Ercan, I.; Lima-Tenório, M.K.; Tenório-Neto, E.T.; Kaewsaneha, C.; Elaissari, A. 2 - Magnetic and pH-responsive magnetic nanocarriers. In Stimuli Responsive Polymeric Nanocarriers for Drug Delivery Applications; Makhlouf, A.S.H.; Abu-Thabit, N.Y., Eds.; Woodhead Publishing Series in Biomaterials, Woodhead Publishing, 2019; pp. 37-85.

137. Alkire, R., Electrochemistry. In Electrochemical Engineering; John Wiley \& Sons, Ltd, 2018; chapter 13, pp. 83-97.

138. Arulmani, S.; Anandan, S.; Ashokkumar, M. Chapter 1 - Introduction to Advanced Nanomaterials. In Nanomaterials for Green Energy; Bhanvase, B.A.; Pawade, V.B.; Dhoble, S.J.; Sonawane, S.H.; Ashokkumar, M., Eds.; Micro and Nano Technologies, Elsevier, 2018; pp. $1-53$.

139. Golovin, Y.I.; Stolyarov, R.A.; Shuklinov, A.V. Electrodeposition of Nickel Particles and their Characterization. Tech. Phys. 2013, 58, 1189-1193.

140. Martínez, G.T.; Zavala, G.; .; Videa, M. Electrodeposition of Nickel Particles and their Characterization. J. Mex. Chem. Soc. 2009, 53, 7-11.

141. Salinas-Quezada, M.P.; Crespo-Yapur, D.A.; Cano-Marquez, A.; Videa, M. Electrocatalytic Activity of Galvanostatically Deposited Ni Thin Films for Methanol Electrooxidation. Fuel Cells 2019, 19, 587-593.

142. Nakano, H.; Matsuno, M.; Oue, S.; Yano, M.; Kobayashi, S.; Fukushima, H. Mechanism of Anomalous Type Electrodeposition of Fe-Ni Alloys from Sulfate Solutions. Mater. Trans. 2004, 45, 3130-3135.

143. Dmitrievich, T.R. Normal Electrochemical Deposition of NiFe Films. Advances in Research 2017, 11, 1-10.

144. Ullal, Y.; Hegde, A.C. Electrodeposition and electro-catalytic study of nanocrystalline Ni-Fe alloy. Int. J. Hydrog. Energy 2014, 39, 10485-10492.

145. Pavithra, G.; Hegde, A.C. Magnetic property and corrosion resistance of electrodeposited nanocrystalline iron-nickel alloys. Appl. Surf. Sci. 2012, 258, 6884-6890.

146. Torabinejad, V.; Aliofkhazraei, M.; Assareh, S.; Allahyarzadeh, M.; Rouhaghdam, A.S. Electrodeposition of Ni-Fe alloys, composites, and nano coatings-A review. J. Alloys Compd. 2017, 691, 841-859. 
147. Ritzert, N.L.; Moffat, T.P. Ultramicroelectrode Studies of Self-Terminated Nickel Electrodeposition and Nickel Hydroxide Formation upon Water Reduction. J. Phys. Chem. C 2016 120, 27478-27489.

148. Quezada, M.P.S. Mechanistic study of methanol electro-oxidation on nickel thin films. PhD thesis, Tecnologico de Monterrey, Monterrey, NL, 2020.

149. Hu, F.; Zhu, S.; Chen, S.; Li, Y.; Ma, L.; Wu, T.; Zhang, Y.; Wang, C.; Liu, C.; Yang, X.; Song, L.; Yang, X.; Xiong, Y. Amorphous Metallic NiFeP: A Conductive Bulk Material Achieving High Activity for Oxygen Evolution Reaction in Both Alkaline and Acidic Media. Adv. Mater. 2017, 29, 1606570.

150. Zeng, L.; Liu, Z.; Sun, K.; Chen, Y.; Zhao, J.; Chen, Y.; Pan, Y.; Lu, Y.; Liu, Y.; Liu, C. Multiple modulations of pyrite nickel sulfides via metal heteroatom doping engineering for boosting alkaline and neutral hydrogen evolution. J. Mater. Chem. A 2019, 7, 25628-25640.

151. Yang, Y.; Wei, P.; Hao, Z.; Yu, Q.; Liu, H.; Liu, L. Adjustable Ternary FeCoNi Nanohybrids for Enhanced Oxygen Evolution Reaction. Chem. Eur. J. 2019, 25, 15361-15366.

152. Long, X.; Li, J.; Xiao, S.; Yan, K.; Wang, Z.; Chen, H.; Yang, S. A Strongly Coupled Graphene and FeNi Double Hydroxide Hybrid as an Excellent Electrocatalyst for the Oxygen Evolution Reaction. Angew. Chem. Int. Ed. 2014, 53, 7584-7588.

153. Smith, R.D.L.; Prévot, M.S.; Fagan, R.D.; Trudel, S.; Berlinguette, C.P. Water Oxidation Catalysis: Electrocatalytic Response to Metal Stoichiometry in Amorphous Metal Oxide Films Containing Iron, Cobalt, and Nickel. J. Am. Chem. Soc. 2013, 135, 11580-11586.

154. Xu, K.; Chen, P.; Li, X.; Tong, Y.; Ding, H.; Wu, X.; Chu, W.; Peng, Z.; Wu, C.; Xie, Y. Metallic Nickel Nitride Nanosheets Realizing Enhanced Electrochemical Water Oxidation. J. Am. Chem. Soc. 2015, 137, 4119-4125.

155. Louie, M.W.; Bell, A.T. An Investigation of Thin-Film Ni-Fe Oxide Catalysts for the Electrochemical Evolution of Oxygen. J. Am. Chem. Soc. 2013, 135, 12329-12337.

156. Gong, M.; Li, Y.; Wang, H.; Liang, Y.; Wu, J.Z.; Zhou, J.; Wang, J.; Regier, T.; Wei, F.; Dai, H. An Advanced Ni-Fe Layered Double Hydroxide Electrocatalyst for Water Oxidation. J. Am. Chem. Soc. 2013, 135, 8452-8455.

157. Klaus, S.; Cai, Y.; Louie, M.W.; Trotochaud, L.; Bell, A.T. Effects of Fe Electrolyte Impurities on $\mathrm{Ni}(\mathrm{OH})_{2} / \mathrm{NiOOH}$ Structure and Oxygen Evolution Activity. J. Phys. Chem. C 2015, $119,7243-7254$.

158. Bediako, D.K.; Lassalle-Kaiser, B.; Surendranath, Y.; Yano, J.; Yachandra, V.K.; Nocera, D.G. Structure-Activity Correlations in a Nickel-Borate Oxygen Evolution Catalyst. J. Am. Chem. Soc. 2012, 134, 6801-6809.

159. Trotochaud, L.; Young, S.L.; Ranney, J.K.; Boettcher, S.W. Nickel-Iron Oxyhydroxide OxygenEvolution Electrocatalysts: The Role of Intentional and Incidental Iron Incorporation. J. Am. Chem. Soc. 2014, 136, 6744-6753.

160. Axmann, P.; Glemser, O. Nickel hydroxide as a matrix for unusual valencies: the electrochemical behaviour of metal(III)-ion-substituted nickel hydroxides of the pyroaurite type. $J$. Alloys Compd. 1997, 246, 232-241.

161. Ahn, H.S.; Bard, A.J. Surface Interrogation Scanning Electrochemical Microscopy of Ni1-xFexOOH $(0<x<0.27)$ Oxygen Evolving Catalyst: Kinetics of the "fast" Iron Sites. J. Am. Chem. Soc. 2016, 138, 313-318.

162. Martirez, J.M.P.; Carter, E.A. Unraveling Oxygen Evolution on Iron-Doped $\beta$-Nickel Oxyhydroxide: The Key Role of Highly Active Molecular-like Sites. J. Am. Chem. Soc. 2019, 141, 693-705.

163. Zhuo, J.; Cabán-Acevedo, M.; Liang, H.; Samad, L.; Ding, Q.; Fu, Y.; Li, M.; Jin, S. HighPerformance Electrocatalysis for Hydrogen Evolution Reaction Using Se-Doped Pyrite-Phase Nickel Diphosphide Nanostructures. ACS Catal. 2015, 5, 6355-6361.

164. Garcia, A.C.; Touzalin, T.; Nieuwland, C.; Perini, N.; Koper, M.T.M. Enhancement of Oxygen Evolution Activity of Nickel Oxyhydroxide by Electrolyte Alkali Cations. Angew. Chem. Int. Ed. 2019, 58, 12999-13003.

165. Dette, C.; Hurst, M.R.; Deng, J.; Nellist, M.R.; Boettcher, S.W. Structural Evolution of Metal (Oxy)hydroxide Nanosheets during the Oxygen Evolution Reaction. ACS Appl. Mater. Interfaces 2019, 11, 5590-5594.

166. Liu, P.; Rodriguez, J.A. Catalysts for Hydrogen Evolution from the [NiFe] Hydrogenase to the $\mathrm{Ni}_{2} \mathrm{P}(001)$ Surface: The Importance of Ensemble Effect. J. Am. Chem. Soc. 2005, 127, 14871-14878. 
167. Greeley, J.; Jaramillo, T.F.; Bonde, J.; Chorkendorff, I.; Nørskov, J.K. Computational highthroughput screening of electrocatalytic materials for hydrogen evolution. Nat. Mater. 2006, 5, 909-913.

168. Man, H.W.; Tsang, C.S.; Li, M.M.J.; Mo, J.; Huang, B.; Lee, L.Y.S.; chung Leung, Y.; Wong, K.Y.; Tsang, S.C.E. Transition metal-doped nickel phosphide nanoparticles as electro- and photocatalysts for hydrogen generation reactions. Appl. Catal. B 2019, 242, 186-193.

169. Xu, Y.F.; Gao, M.R.; Zheng, Y.R.; Jiang, J.; Yu, S.H. Nickel/Nickel (II) Oxide Nanoparticles Anchored onto Cobalt (IV) Diselenide Nanobelts for the Electrochemical Production of Hydrogen. Angewandte Chemie - International Edition 2013, 52, 8546-8550.

170. Wu, Z.; Li, X.; Liu, W.; Zhong, Y.; Gan, Q.; Li, X.; Wang, H. Materials Chemistry of Iron Phosphosulfide Nanoparticles: Synthesis, Solid State Chemistry, Surface Structure, and Electrocatalysis for the Hydrogen Evolution Reaction. ACS Catal. 2017, 7, 4026-4032.

171. Lima, D.W.; Trombetta, F.; de Paula Benvenutti, P.; Teixeira, S.R.; Martini, E.M. Effect of different carbon supports for Ni particles for the HER in tetra-alkylammonium-sulfonic acid media. Int. J. Energy Res. 2019, 43, 7352-7363.

172. Oriňáková, R.; Trnková, L.; Gálová, M.; Šupicová, M. Application of elimination voltammetry in the study of electroplating processes on the graphite electrode. Electrochim. Acta 2004, $49,3587-3594$.

173. Yang, M.; Compton, R.G. Adsorption processes coupled with mass transport at macroelectrodes: New insights from simulation. J. Electroanal. Chem. 2019, 836, 68-76.

174. Oriňáková, R.; Strečková, M.; Trnková, L.; Rozik, R.; Gálová, M. Comparison of chloride and sulphate electrolytes in nickel electrodeposition on a paraffin impregnated graphite electrode. J. Electroanal. Chem. 2006, 594, 152-159. 
